University of Louisville

ThinkIR: The University of Louisville's Institutional Repository

Electronic Theses and Dissertations

$5-2017$

\title{
A meta-analysis of the longitudinal relationship between adolescent depression and academic achievement.
}

Rachel E. Buehner

University of Louisville

Follow this and additional works at: https://ir.library.louisville.edu/etd

Part of the Developmental Psychology Commons, Educational Psychology Commons, School

Psychology Commons, and the Student Counseling and Personnel Services Commons

\section{Recommended Citation}

Buehner, Rachel E., "A meta-analysis of the longitudinal relationship between adolescent depression and academic achievement." (2017). Electronic Theses and Dissertations. Paper 2721.

https://doi.org/10.18297/etd/2721

This Doctoral Dissertation is brought to you for free and open access by ThinkIR: The University of Louisville's Institutional Repository. It has been accepted for inclusion in Electronic Theses and Dissertations by an authorized administrator of ThinkIR: The University of Louisville's Institutional Repository. This title appears here courtesy of the author, who has retained all other copyrights. For more information, please contact thinkir@louisville.edu. 


\title{
A META-ANALYSIS OF THE LONGITUDINAL RELATIONSHIP BETWEEN ADOLESCENT DEPRESSION AND ACADEMIC ACHIEVEMENT
}

\author{
By \\ Rachel E. Buehner \\ B.A., University of Louisville, 2003 \\ M.Ed., University of Louisville, 2009 \\ A Dissertation \\ Submitted to the Faculty of the \\ College of Education and Human Development of the University of Louisville \\ in Partial Fulfillment of the Requirements \\ for the Degree of
}

Doctor of Philosophy in Counseling and Personnel Services

Department of Counseling and Human Development

University of Louisville

Louisville, KY

May 2017 
Copyright 2017 by Rachel Elizabeth Buehner

All rights reserved 



\title{
A META-ANALYSIS OF THE LONGITUDINAL RELATIONSHIP BETWEEN ADOLESCENT DEPRESSION AND ACADEMIC ACHIEVEMENT
}

\author{
By \\ Rachel E. Buehner \\ B.A., University of Louisville, 2003 \\ M.Ed., University of Louisville, 2009 \\ A Dissertation Approved on
}

April 18, 2017

by the following Dissertation Committee

\begin{tabular}{c}
\hline $\begin{array}{c}\text { Dissertation Director } \\
\text { Patrick Pössel, Dr. rer. Soc. }\end{array}$ \\
\hline $\begin{array}{c}\text { Dissertation Co-Director } \\
\text { Jeffrey Valentine, Ph.D. }\end{array}$ \\
\hline
\end{tabular}

A. Scott LaJoie, Ph.D.

Patrick Hardesty, Ph.D. 


\section{DEDICATION}

To D. Thank you for climbing this mountain with me. 


\section{ACKNOWLEDGEMENTS}

A lot of people provided a lot of support and cheering to help me bring this project and degree to fruition. First, I wish to extend my thanks to my work family for supporting my efforts to complete a dissertation while I work and have more babies. I am lucky to have landed in a place where I can enjoy my career while I begin a family, all while making this dissertation a reality. Thanks in particular are due to my supervisor, Dr. Brian King, for his endless support of my advancement and his unrelenting validation of my efforts.

Drs. Patrick Hardesty and Scott LaJoie have been agreeable, upbeat, warm, and knowledgeable at every turn. Thanks to you both for being parts of my committee, for giving insightful guidance as well as moral support where needed. I have appreciated your input during the many, many years (more than a decade!) that we've worked together.

Dr. Jeff Valentine has continuously provided patient wisdom and guidance, and allowed me to grow in confidence and ability during the course of this project. You have helped me in immeasurable ways to become a better and kinder therapist, just by pushing me (ever so patiently) to expand my skills set and see academic challenges as opportunities and even as fun. Thank you for your mentorship and for being my coding partner and guide. 
To Dr. Patrick Pössel... thank you. You have pushed me and mentored me. You've set an extraordinary example of what kindness, work ethic, knowledge, and scientific rigor look like wrapped up in one person. The contributions you've made to the field and to the community and to my life are immeasurable. You never gave up on me.

My parents and sisters deserve acknowledgements for the unending love and cheerleading they've provided to help me to this finishing point. Dad, you have always, always made me feel like I am doing something important, and that the effort is worth it to help the people in the world who need me. You've continuously reminded me of the mission, and for that I am grateful to you. Mom, you deserve pages and pages of acknowledgements for the unconditional and never ending love you've given to me throughout this journey. Thank you for setting an example of working hard and balancing earnest professionalism with being a great mother. I have always known that you were with me as I chose this road, and that, in the words of Robert Frost, made all the difference.

In the course of writing this dissertation, I've had three children. Someday kids, I will tell you about why I undertook this endeavor while you were so young. Please know that the time I spent on finishing this project is meant to help me eventually reach more people who need support and help in this world. You are all smart, loving, little people and I know you, like me, will help the world to be a happier place. I am so, so proud to be your mother.

Finally, to my husband, we did it! From the moment we've met, you never stopped telling me that I can do everything that I set my mind to. From internship to job applications to dissertation, not to mention having three great kids, you and I have 
accomplished so much so fast, and the fun is just beginning. Thank you for your strength, thank you for your nudging, thank you for making it work. You've been such a good partner to me through this journey. I love you. 


\title{
ABSTRACT \\ A META-ANALYSIS OF THE LONGITUDINAL RELATIONSHIP BETWEEN ADOLESCENT DEPRESSION AND ACADEMIC ACHIEVEMENT
}

\author{
Rachel Elizabeth Buehner
}

April 18, 2017

Researchers in the fields of both education and mental health endeavor to develop and implement interventions which will bring children and adolescents greater academic success and optimally address mental health issues. Educators seek to target risk factors which might impede a student's success in the classroom, while mental health providers seek to reduce issues within a child's environment which might be risk factors for depression. Evidence for a cross-sectional relationship between adolescent depression and academic achievement is well-supported, with depression and achievement being negatively correlated in adolescents. The longitudinal relationship between these two variables is not fully understood, however. While primary studies provide evidence of a negative longitudinal correlation between depression and achievement among adolescents (Haines, Norris, \& Kashy, 1996), to date there has yet to be a state-of-the-art metaanalysis that aggregates and examines the bidirectional relationship between depression and achievement over time. The purpose of this analysis is to fill this gap, with an exploration of the magnitude of the relationship between achievement and depression, as well as consideration of moderators which may impact the relationships between depression and achievement over time. Longitudinal studies $(\mathrm{N}=26)$ that assess both depression scores and achievement at multiple time points were synthesized in order to estimate the overall relationship between the variables, and to elucidate the role of moderator variables which may impact any relationship over time, including biological 
sex, age, lapse between data waves, and method of measurement of both achievement and depression. The intention of the current study is to enhance the ability to predict scholastic or mental health issues, and to understand whether methodological considerations might better target when and for whom achievement and depressive issues are most correlated. Results indicate a small but statistically significant relationship between achievement and subsequent depression $(r=-.0824, \mathrm{p}<.0001,95 \% \mathrm{CI}=-$ 0.1171 to -.0478$)$. The relationship between depression and subsequent achievement was not statistically significant. None of the above mentioned variables examined as potential moderators were statistically significant.

Keywords: depression, adolescent, achievement, meta-analysis 
TABLE OF CONTENTS

PAGE

DEDICATION $\quad$.................................................. iii

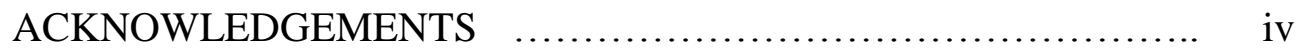

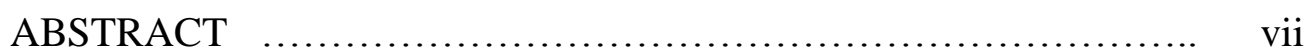

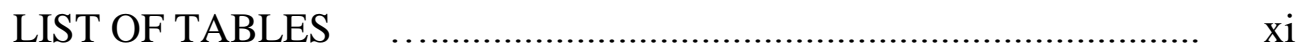

CHAPTER I INTRODUCTION $\quad$.................................. 1

Relationship Between Depression and Achievement ............ 1

Mechanisms Explaining the Association Between

Depression and Achievement .............................. 4

Moderators of the Relationship Between Depression

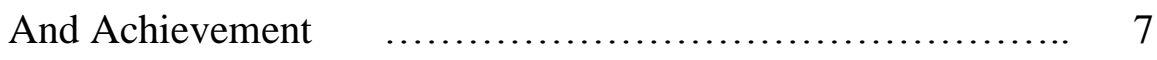

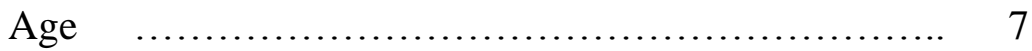

Lapse Between Data Waves $\quad \ldots \ldots \ldots \ldots \ldots \ldots \ldots \ldots \ldots . . \ldots$

Biological Sex ................................... 10

Measure of Depression $\quad$......................... 11

Measure of Achievement $\quad$........................... 13

The Current Study $\quad$................................................................ 14

CHAPTER II METHODS $\quad$....................................... 17

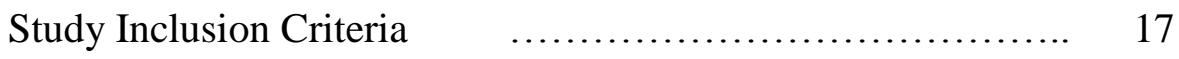

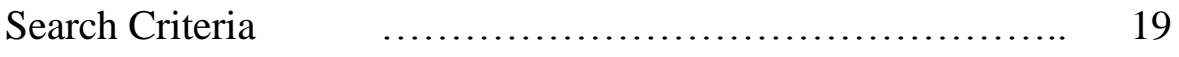

Date and Form of Publications $\quad \ldots \ldots \ldots \ldots \ldots \ldots \ldots \ldots \ldots . . . \ldots 19$ 
Study Inclusion Decision-Making $\quad \ldots \ldots \ldots \ldots \ldots \ldots \ldots \ldots \ldots . \ldots . \ldots . \ldots . \ldots$

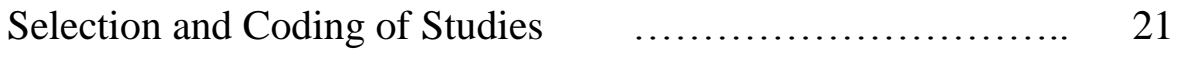

Meta-analytic Model Selection $\quad$....................... 21

Effect Size Calculation $\quad$............................ 22

Moderator Analysis $\quad \ldots \ldots \ldots \ldots \ldots \ldots \ldots \ldots \ldots \ldots \ldots \ldots \ldots . \ldots \ldots$

Funnel Plot and Trim and Fill Analyses $\quad \ldots \ldots \ldots \ldots \ldots \ldots . . \ldots 24$

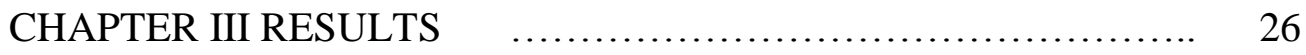

Depression and Subsequent Achievement $\quad \ldots \ldots \ldots \ldots \ldots \ldots . . . . . .27$

Achievement and Subsequent Depression $\quad \ldots \ldots \ldots \ldots \ldots \ldots . . . . . . .30$

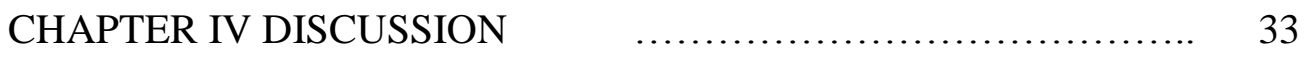

Moderator Variables $\ldots \ldots \ldots \ldots \ldots \ldots \ldots \ldots \ldots \ldots \ldots \ldots \ldots . \ldots \ldots \ldots$

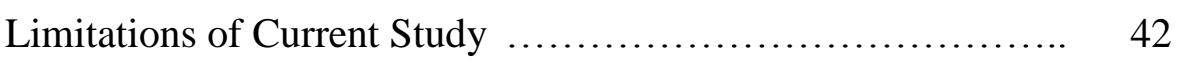

Areas for Future Research $\quad \ldots \ldots \ldots \ldots \ldots \ldots \ldots \ldots \ldots \ldots \ldots . . \ldots \ldots \ldots, 44$

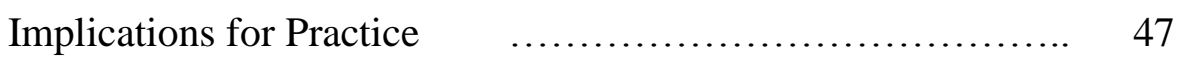

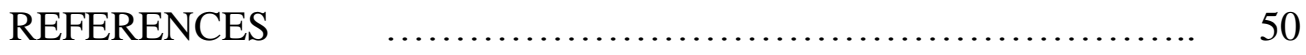

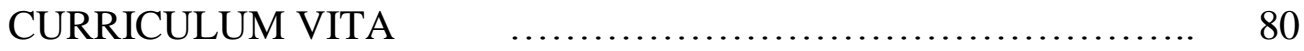




\section{LIST OF TABLES}

TABLE

PAGE

1. Strategy for Electronic Searches

2. Screening Guide for Depression and Achievement Meta-Analysis

3. Coding Guide 64

4. References of Included Studies

5. Publication and Methodology Information for Included Studies 73

6. Trim and Fill Analysis 75 


\section{CHAPTER I INTRODUCTION AND LITERATURE REVIEW}

Depression can be characterized by feelings of worthlessness, diminished interest or pleasure in daily activities, depressed mood, reduced concentration or focus, lack of motivation, and suicidality or thoughts of death (American Psychiatric Association, 2015). Symptoms of depression often manifest before age 18 and continue into adulthood (Weissman, Goldstein, Moreau, Adams, Greenwald, et al., 1999). Incidence rates of depression among adolescents continue to rise precipitously in the United States, with over three million adolescents having sought treatment for a major depressive episode in the past twelve months and a higher percentage of adolescents reporting having sought recent treatment for a depressive episode in 2015 than reported annually in the years 2004-2014 (National Survey on Drug Use and Health, Substance Abuse and Mental Health Services Administration, 2015). Depression is frequently co-morbid with other psychological disorders, including anxiety, conduct disorders, and substance abuse (Angold \& Costello, 1993; Gladstone \& Beardslee, 2009). In numerous cross-sectional studies of achievement and depression, depression and academic achievement are found to be negatively associated (Fauber, Forehand, Long, Burke, \& Faust, 1987; Patterson \& Capaldi, 1990; Patterson \& Stoolmiller, 1991).

\section{Relationship Between Depression and Achievement}

The following review of empirical findings, first of results related to depression and subsequent achievement, followed by a review of studies of achievement and 
subsequent depression, is meant to evidence the significance of the longitudinal interrelationship between these two constructs and to add to our understanding of how best to predict depressive and academic issues. With regard to the impact of depression on subsequent achievement, clinically depressed children are more likely than nondepressed children to incur academic difficulties, and there is longitudinal evidence that childhood depression may be a risk factor for academic difficulties in a child's future (Bardone, Moffitt, Casi, \& Dixon, 1996; Bernstein \& Borchardt, 1991; Kovacs \& Devlin, 1998). Hishinuma, McArdle, \& Chang (2012) reported a statistically significant relationship between depression and subsequent achievement among a large, ethnically diverse sample of adolescents. Roeser, Eccles, \& Sameroff (2000) reported a statistically significant relationship between depression and subsequent achievement among a sample of middle school students. Depression among middle school-aged children is associated with increased dropout rates, (Quiroga, Janosz, Bisset, \& Morin, 2013) and adolescent depression has a statistically significant, negative impact on graduation rates and postsecondary education (Fletcher 2008; Needham 2009). Fletcher (2008) found that depressive symptoms were negatively correlated with years of schooling. Other studies obtained results indicating that depression is in fact not associated with subsequent achievement. Patterson \& Stoolmiller (1991) did not find a statistically significant relationship between depression and subsequent achievement in an all-male sample. Cole, Martin, Powers, and Truglio (1996), on the other hand, failed to find any correlation between depression and subsequent achievement. Similarly, there is evidence from largescale longitudinal studies that depression is not correlated with subsequent educational attainment. Breslau, Lane, Sampson, \& Kessler (2008) found no statistically significant 
relationship between depression and subsequent achievement in a sample of adults who provided retrospective data related to childhood indicators of achievement and mental health. Miech, Caspi, Moffitt, Wright, \& Silva (1999) reported that depression at age 15 was not statistically significantly related to either completion of educational certificate or continuation on to secondary schooling. Hanson, Austin, \& Lee- Bayha, (2004) similarly found no correlation between depression and subsequent achievement in their examination of risk factors for depression among adolescents. Other longitudinal studies have yielded results that indicate depression negatively impacts graduation rates, but only among females (Berndt, Koran, Finkelstein, Gelenberg, Kornstein, Miller, et al., 2000; Needham, 2009). Mikami and Hinshaw (2006) also found that depression and subsequent achievement were negatively, statistically significantly correlated among participants in an all-female sample.

A search for studies in which correlations between achievement and subsequent depression were reported yielded fewer results than for the above described correlation between depression and subsequent achievement. A decrease in school performance (as measured by a drop in GPA) is associated with worsening severity of depressive symptoms (Fröjd, Nissinen, Pelkonen, Marttunen, Koivisto, \& Kaltiala-Heino, 2008). Feshbach and Feshbach (1987) describe a longitudinal sequence in which depressive symptomology at ages 8 and 9 predicts poorer academic performance two years later, particularly for girls. Undheim and Sund (2005) similarly found that a statistically significant longitudinal relationship between achievement and subsequent depression, only among female participants. Huang's 2015 meta-analysis of 43 studies related to achievement and subsequent depression indicated that biological sex was not a 
statistically significant moderator of the relationship between achievement and subsequent depression.

\section{Mechanisms Explaining the Associations between Depression and Achievement}

The above described findings raise questions regarding what mechanism(s) might explain the associations between depression and academic achievement. First, one of the symptoms of depression is poor concentration (American Psychiatry Association, 2015). In addition, negative affect, a hallmark symptom of depression, is negatively correlated with concentration and performance on memory-related tasks (Dux, et al., 2008) and cognitive tasks (Kaslow, Rehm, \& Siegel, 1984). As poor concentration, memory problems, and low performance on cognitive tasks are associated with low academic achievement (Dux et al., 2008), it seems obvious that depression and academic achievement are negatively associated. In addition, it may be that issues in one area of a child's life have effects on other domains of functioning. Masten et al. (2005) describe developmental cascades in which deficits in one part of a child's life have cascading effects into other areas of that child's life. This model provides a possible framework for conceptualizing how depression and achievement issues might impact one another, potentially altering a child's developmental course. Performance in different domains do not operate independently of one another, and well-being in one area of a child's life can act as a promotive or protective function for a child with regard to their performance in another domain of their life. Conversely, problems in one domain of a child's life can also have negative impacts on other areas of that child's life (Masten, Best, \& Garmezy, 1990). To what degree achievement problems impact a child's mental health, and how 
much mental health issues might impact academic functioning, are questions for the current study.

A different explanation for the association between achievement and depression can be found in form of the cognitive diathesis-stress models explaining the development and maintenance of depression. Cognitive diatheses are individual psychological characteristics or patterns which likely develop early in life and manifest as predispositions toward certain behaviors or reactions (O’Hara, 1995). Cognitive diathesis-stress theories conceptualize depression as the result of particular cognitive diatheses interacting with difficult or stressful events such as academic problems (Hammen, 2005). While these models share a negative cognitive pattern + negative event conceptualization of depression, they differ on the specific cognitive mechanisms underlying the disorder. As an example, the response styles theory of depression (NolenHoeksema, 1991) describes distinct reaction styles to negative events and the ways in which these varying responses may alter the course of depressive symptoms (NolenHoeksema, 1991). After a negative event (such as a bad grade or poor performance on a test), an individual might either ruminate about their feelings and response to the event, find ways to distract themselves from thoughts of the event, or engage in problem-solving behavior (Hilt, McLaughlin, \& Nolen-Hoeksema, 2010). Thus, problems with academic achievement act as a stressor interacting with an individual's cognitive diathesis such as rumination, and depression may develop as a result. Conversely, attributional style may also impact the relationship between depression and subsequent achievement. An attributional style in which positive events are attributed to stable, internal, and global causes is correlated with higher academic performance, particularly in low-achieving 
schools (Houston, 2015). In that study, when stable attributions were made related to negative events, these were statistically significantly correlated with academic performance, particularly in high achieving schools. That author summarized the role of attributional style in predicting achievement: "Stable and internal attributional style can lead to better academic performance" (page 198).

Another possible explanation for the association between achievement and depression relates to the concept of competence, defined as the "multidimensional characteristics of a learner - including skills, attitudes, and behaviors - that factor into academic success" (Kreutzer, deLuca, \& Caplan, 2011, page 12). Cole (1991) describes a sequence in which problems (such as those related to competency in the academic arena) can result in the development of negative self-schemata, a well-established diathesis of depression (Kovacs \& Beck, 1978). To be more precise, a student may receive a low grade or test score, and begin to internalize this feedback as indicative that they are not competent. From the feedback (low grade), the internalized messages then morph into a feeling that one is incompetent (rather than this low mark being a reflection on the one performance), which may lead to depressive symptoms.

What remains unclear based on any of the above described models and mixed results from primary studies is whether any longitudinal relationship between achievement and depression in fact exists, when any relationships are strongest, and how moderating variables may impact the strength of the achievement - depression relationship over time. Interventions to address adolescent depression and achievement concerns can conceivably be better targeted once it is clearer when the relationships and directionality peaks. While cross-sectional studies have determined that depression is 
associated with poor academic outcomes (Bardone, et al., 1996; Bernstein et al., 1991;

Dux et al., 2008; Fröjd, et al., 2008; Hishinuma et al., 2012; Kaslow et al., 1994; Kovacs

et al., 1998), the longitudinal relationship between these two variables is not fully

understood. In addition, the direction of the relationship between achievement and depression likely is moderated by different variables over time, however there are mixed results regarding whether and the degree to which moderators impact the relationship between achievement and depression over time (Huang, 2015; Latendresse, 2004;

Colarossi, 2000).

\section{Moderators of the Relationship Between Achievement and Depression}

Certain study participant characteristics and methodological variables may moderate the relationship between achievement and depression among adolescents. These include age at which depression and achievement are measured, biological sex of study participants, time elapsed between data waves, as well as the metrics used to measure depression and to describe achievement.

\section{Age}

Among children and adolescents, the emergence of depressive symptoms typically peaks between the ages of 13 and 16, then usually exhibits a plateau or will decrease during later years of adolescence (Ge, Natsuaki, \& Conger, 2006; Wichstrom, 1999). Various models of development and depression attempt to explain ways in which children are differentially susceptible to the effects of depressive symptoms and academic problems based upon their respective ages. The following is a review of two such models, in addition to cross-sectional results which describe previous findings that younger 
children are more impacted by issues related to achievement and depression than older children and adolescents.

First, Cole's (1997) competency-based model of depression describes younger children as being more influenced by the evaluative feedback of teachers and caregivers than older adolescents, who more greatly value the input of peers over the feedback of caregivers or teachers. Similar to the looking glass hypothesis, in which individuals shape their self-perceptions based on how others view them (Cooley, 1902), Cole et al. (2001) found that children became more prone to assume the opinions of others as they move from middle childhood into adolescence, and evaluative feedback from teachers such as a failing grade could lead to a generalized sense of incompetence, which may put the child at risk for depressive symptoms. Espousing a cascading effects conceptualization of early achievement issues, learning problems in younger years often foretell of both future learning issues (Masten et al., 2005), as well as subsequent depression problems (Topitzes, Godes, Mersky, Ceglarek, \& Reynolds, 2009).

There is evidence that the cross-sectional correlation between achievement and depression is weaker for older adolescents than for younger children (Topitzes et al., 2009), that younger children may also be more sensitive to feedback related to negative academic performance than older children (Rudolph, Lambert, Clark, \& Kurlakowsky, 2001), and that school difficulties act as a risk factor for children up through the middle school years (Herman, Lambert, Ialongo, \& Ostrander, 2007)). Further, Huang's (2015) meta-analysis finding that previous achievement has a stronger association with subsequent depression for children at ten years old $(r=-.20)$ than for participants 
assessed at age $20(r=-.10)$ indicate that achievement is more strongly correlated to subsequent depression in children and younger adolescents than to depression in adults.

Understanding of when the depression/achievement correlation is most and least pronounced may help to foster support for age appropriate interventions to assess depression symptoms and academic assistance when it is most needed. Thus, the current study seeks to examine the bidirectional relationship between depression and achievement, including whether age of participants impacts how these variables possibly affect one another over time. Based on Cole's (1997) competency-based model of depression, cross-sectional studies (Topitzes et al., 2009; Herman et al., 2007; Rudolph et al., 2001), and Huang's meta-analysis of achievement and subsequent depression (2015) it is hypothesized that the correlation between achievement and subsequent depression will be stronger for younger children than for older children. With regard to depression and subsequent achievement, the aforementioned results from cross-sectional studies in which this relationship is strongest among younger children lead to a hypothesis that this relationship will, in fact, be strongest among younger children relative to their older peers.

\section{Lapse Between Data Waves}

Grimm (2007) reports that few primary longitudinal studies have explored whether the lapse(s) of time between data waves when achievement and depression data are collected impacts the strengths of the association between depression and achievement. In the empirical part of this study, Grimm found no statistically significant change in the correlation between achievement and subsequent depression depending on the lapse of time between data waves. This result indicates that the relationship between 
achievement and subsequent depression did not diminish over time. Grimm's findings, Huang's 2015 meta-analysis of on the relationship between achievement and subsequent depression indicated that the correlation between achievement and future depression weakens over time, such that "for every 1-year increase in the time interval between waves of data collection the correlation between academic achievement and subsequent depression was expected to decrease by an average of .01 unit in studies with a time interval shorter than 19 years" (page 439). A review of relevant literature indicates that other than Grimm and those studies included in Huang's analysis, lapses between data waves remains an area largely unexamined in previous longitudinal studies. Any possible moderating effect of lapse between data waves is relevant as interventions to address scholastic or mood-related issues among adolescents might best be targeted once it is determined how long of a "window" administrators and mental health professionals optimally have to address issues in the academic and mental health realms once problems are detected.

\section{Biological Sex}

In her seminal article “Early Childhood Experiences and Women's Achievement Motivations," Lois Hoffman (1972) describes female achievement as "motivated by a desire for love, rather than mastery" (p. 136). Girls may be more sensitive to social problems, including those which might impact the academic realm such as social awkwardness or issues with speech, than their male counterparts (Oldehinkel, Rosmalen, Veenstra, Dijkstra, \& Ormel, 2007). Further, girls tend to attribute poor academic performance to their low competence or abilities, whereas boys tend to view their academic potential more positively (Frey \& Ruble, 1987). Both considerations would hint 
at a stronger relationship between achievement and depression for girls than for boys. These theoretical considerations are supported by several cross-sectional studies that found achievement and subsequent depression to be more strongly correlated among girls than boys (Herman et al., 2008; McCarty, Mason, Kosterman, Hawkins, Lengua, \& McCauley, 2008). Derdikmon-Eiron et al. (2001) on the other hand found that the negative correlation between depression and academic performance was stronger among boys than girls. Finally, in longitudinal studies including Latendresse (2004) and Colarossi (2000), biological sex did not moderate the relationship between achievement and subsequent depression. Huang's (2015) meta-analysis of achievement on subsequent adolescent depression confirmed the findings of those longitudinal studies. In other words, Huang found no difference in the correlation between prior academic achievement and subsequent depression based on biological sex. However, whether and to what degree biological sex impacts the association from depression to subsequent achievement is unclear and is examined in the current meta-analysis. In light of the results from the aforementioned studies in which biological sex did not moderate the longitudinal relationship between achievement and depression (Latendresse, 2004; Colarossi, 2000), and Huang's meta-analysis (2015), it is hypothesized that biological sex does not moderate the relationship between these variables over time.

\section{Measure of Depression}

Huang's 2015 meta-analysis yielded a small but not statistically significant moderating effect of depression measure on achievement and subsequent depression. In a post hoc analysis, Huang focused on three main measures, all self-report assessments, to explore whether depression measure might moderate the relationship between 
achievement and depression: The Children's Depression Inventory (CDI, Kovacs, 1992), the Center for Epidemiologic Studies Depression Scale (CES-D, Radloff, 1977) and the Beck Depression Inventory - Second Edition (BDI-II, Beck, Steer, \& Brown, 1996). The CES-D, (Radloff, 1977)' is indicated for use with adolescents aged fourteen years old and older (Muller \& Erford 2012), while the BDI-II (Beck, Steer, \& Brown, 1996), is a questionnaire that measures the intensity of depression in individuals aged 13 years and older (Beck \& Steer 1993). Finally, the CDI (Kovacs, 1992) is an instrument administered with children and adolescents aged seven to seventeen. The CES-D and BDI are both desirable for use in clinical and research settings due to their relatively low costs and ease of administration and scoring (Sharp \& Lipsky, 2002). These measures for assessing depressive symptoms are highly correlated with one another, making comparisons of their moderating effects on the correlation between achievement and depression feasible. In the 2015 meta-analysis of on the relationship between achievement and subsequent depression, Huang reported, however, that the mean correlation "was small-to moderate for the CDI and small for the BDI and CES-D" (page 440). The Achenbach Youth Self Report (YSR) is another self-report measure commonly utilized in studies of mental health symptomology among children ages 11-18. It includes clinical and competency related scales, as well as diagnosis-driven scales to enhance diagnostic clarity (Achenbach, Dumenci, \& Rescorla, 2001). Other methods for measuring depressive symptomology include assessments which utilize reports from other informants, such as caregivers and teachers, though it should be noted that there is often discrepancy between the symptomology which is self-reported by children and the symptomology of those children described by their respective caregivers (Cytryn \& 
McKnew, 1980). The Achenbach Child Behavior Checklist (CBCL/6-18), and its

Teacher Report Form (CBCL-TRF) are commonly utilized assessments of symptomology that utilize caregiver and teacher ratings of symptomology among children. The CBCL's Anxiety/Depression narrow-band scale and the parallel TRF allow the rater to describe internalizing behaviors using a 0-4 Likert scale. The empirically-based scales to the CBCL's Anxious/Depressed and Withdrawn/Depressed scales have good internal consistency, with Cronbach's alpha of .84 and .80 , respectively (Achenbach \& Rescorla, 2001).

While Huang's (2015) meta-analysis of achievement and subsequent depression indicated that depression measure did not moderate the relationship, the current metaanalysis seeks to explore whether this is the case for depression and subsequent achievement. Moderator analyses for both directions, achievement to subsequent depression and depression to subsequent achievement, will examine whether the depression measure impacts the correlation between the variables, whether the commonly-utilized CDI impacts the relationship more or less than other measures, and whether the type of informant affects the correlations. Based on Huang's results, a moderating effect of depression measure is not expected.

\section{Measure of Achievement}

Various methods for assessing academic performance and achievement outcomes are available. In cross-sectional studies, the negative correlation between adolescent depression and achievement is evident when observing various academic achievement measures, including standardized tests (Herman et al., 2008) and academic grades (Shahar et al., 2006). These measures for assessing academic achievement are highly 
correlated with one another (D'Agostino \& Powers, 2009). There is, on the other hand, evidence that the way in which achievement is measured can impact the observed correlations between constructs. For example, Roorda, Koomen, Spilt, and Oort (2011) studied the effect of positive teacher-student relationships on achievement. They found that the effect of positive teacher-student relationships on achievement is larger when grades are used as indicators of students' achievement compared to other measures of achievement. Thus, it might be that the way in which achievement is measured has a statistical bearing on the longitudinal relationship between achievement and depression. However, Huang (2015) found that whether achievement was measured using GPA, selfreport or school records, or standardized test scores, had no statistically significant bearing on the relationship between achievement and subsequent depression. Nevertheless, because Huang exclusively focused on analyzing the impact of achievement on subsequent depression, whether the way in which academic achievement is measured bears any impact on any observable relationship between depression and subsequent achievement (the path not examined in Huang's meta-analysis) is a question explored in the current meta-analysis. Based on the results from Huang, (2015), it is expected that the way in which achievement is measured will not moderate the longitudinal relationship between achievement and depression.

\section{The Current Study}

The objective of this study is to examine the relationship between adolescent depression and academic achievement, over time. While a negative cross-sectional association between depression and achievement among adolescents has been demonstrated (Fauber et al., 1987; Patterson et al., 1990; Patterson et al., 1991), whether 
depression predicts changes in academic performance or is a reaction to it remains the question to be explored. Previous large-scale longitudinal studies indicate that depression is not correlated with subsequent educational attainment (Breslau et al., 2008; Hanson et al., 2004; Miech et al., 1999; Needham, 2009), while other studies yielded a statistically significant negative effect of adolescent depression on graduation rates and postsecondary education (Fletcher 2008; Needham 2009). Fewer primary studies examined the impact of achievement on subsequent depression, but there is limited evidence that achievement problems predict future depressive symptomology (Feshbach et al., 1987; Huang, 2015; Undheim et al., 2005).

The purpose of the current study is to clarify the directionality and strength of the relationship between depression and achievement based on multiple time points at which both are measured. Further, examination of whether moderating variables such as participant age, lapse of time between data waves, biological sex, and depression and achievement measures impact the achievement-depression relationship over time is needed. This is especially true in light of the fact that there has yet to be a meta-analysis that examines the directionality of the relationship between depression and achievement over time and relevant moderating variables.

This current study seeks to replicate Huang's (2015) results, in which a statistically significant negative correlation was observed between adolescent achievement and subsequent depression. With regard to the depression to subsequent achievement path, it is hypothesized, based on numerous studies of depression and achievement (Bardone et al., 1996; Bernstein et al., 1991; Kovacs et al., 1998), that there will be a negative correlation between depression and subsequent achievement. Based on 
Cole's (1997) competency-based model of depression, cross-sectional studies (Herman et al., 2007; Rudolph et al., 2001; Topitzes et al., 2009), and Huang's meta-analysis of achievement and subsequent depression (2015) it is further hypothesized that the correlation between achievement and subsequent depression will be stronger for younger children than for older children. With regard to depression and subsequent achievement, the aforementioned results from cross-sectional studies in which this relationship is strongest among younger children lead to a hypothesis that this relationship will, in fact, be strongest among younger children relative to their older peers as well. Further, based on theoretical considerations (Abramson, Seligman, \& Teasdale, 1978; Cole, 1991) and Huang (2015),it is hypothesized that the strengths of the association between achievement and subsequent depression will be statistically significantly impacted by the lapse of time between data waves. While Roorda, et al (2011), on the other hand, found that studies which utilize grades or GPA will evidence a stronger correlation between achievement and depression than those studies in which achievement is measured using standardized testing. Based on Huang's 2015 meta-analysis of 43 studies, it is hypothesized that achievement measures do not moderate the relationship between achievement and subsequent depression. Finally, based on previous empirical data (Colarossi, 2000; Huang, 2015; Latendresse, 2004;) it is predicted that neither biological sex nor depression measure will significantly impact the association between achievement and depression. 


\section{CHAPTER II METHODS}

Two meta-analyses were undertaken: one analysis examined the impact of depression on subsequent achievement, while the other focused on the relationship between achievement and subsequent depression. Based on Huang's (2015) metaanalysis, if the overall average effect size depression on later achievement (controlling for prior achievement) is very small (.06), the typical sample size is about 500, and the degree of heterogeneity is small, then according to Valentine, Pigott, \& Rothstein (2010), the current meta-analyses will need to include 18 studies to have power $>.80$. When determining the number of studies needed to reach a desirable level of statistical power in a meta-analysis, less heterogeneity between studies can result in increased prospective power, while more heterogeneity between included studies often reduces the power in the meta-analysis (Valentine et al., 2010). The current study was completed using a total of 26 studies which met the inclusion criteria described below. The 26 studies included a total of 29 independent samples, and comprised of a total of 31,966 participants (for an average sample size of about 1,100 per independent sample), suggesting that there should be adequate statistical power for the overall analysis given the assumptions derived from Huang's meta-analysis.

\section{Study Inclusion Criteria}

This systematic review involved an exhaustive search for studies that included measures of adolescent depression and achievement, measured at multiple time points. The goal of this study was to aggregate the results of included studies to enhance 
understanding of how achievement and depression affect one another over time. To be included in this review, studies were required to meet several criteria, including (a) assessment of depression at multiple time points; (b) assessment of academic achievement at multiple time points (with acceptable measures of achievement including GPA, self-reports of academic performance, standardized test score(s), grades, and/or grade retention); and (c) sampled participants between the ages of five and eighteen years at the first data collection point. Allowable participants included children and adolescents from a number of various settings and populations, including both clinical and nonclinical populations, special education settings, and children or adolescents experiencing co-morbid physical or mental health issues; no exclusions were made based on comorbid conditions of study participants. A final criterion for inclusion in the current analysis was that studies must have reported a full correlation matrix that incorporated both the correlation between achievement and subsequent depression, and the correlation depression and subsequent achievement. I actively sought to include studies beyond those whose relationships are statistically significant or supportive of the researchers' hypotheses (Higgins \& Green, 2009), referred to broadly as "reporting bias." One approach for reducing the chance of potential outcome reporting bias (one type of reporting bias) is to target studies which include full correlation matrices (because a full correlation matrix presents correlations regardless of their statistical significance). The decision to require a correlation matrix of all of the included studies in the current analysis, then, was made in an effort to capture both statistically significant and nonsignificant correlations for inclusion. 
In an effort to reduce the likelihood of publication bias, I included relevant studies regardless of publication status. Another type of reporting bias, publication bias refers to the tendency for studies that yield statistically significant results (i.e. those which indicate a particular intervention is beneficial or works) to be likely to be published, and therefore be easier to find, and therefore to be more likely to be included in a study such as the current one. This potentially creates biased evidence against the null hypothesis, which could cause overestimation of the overall effect size. Once meta-analysis is completed, post hoc analysis can examine for the presence and potential impact of publication bias.

\section{Search Criteria}

The following search terms were used to capture studies that met the aforementioned inclusion criteria: "Depress* or internaliz* or mood* or affect*". The search terms utilized to find studies analyzing academic achievement were: "Achieve* or attend* or Grade* or GPA or Retent* or Academic*”. To ensure that only studies which included child or adolescent participants were included, the search terms "Child* or Student* or Adolesc*" were employed. Finally, in order to meta-analyze studies which included data at multiple time points, the search terms "longitudinal or prospective or retrospective or time points" were utilized.

\section{Date and Form of Publications}

Several methods were used to develop an exhaustive literature search. Included studies were located through a search of the following electronic databases: Cochrane Database of Systematic Reviews, ERIC, MEDLINE, and PsycInfo. No date limitations were used. Reference lists of all included studies were examined to find additional studies for inclusion. Hand searches of abstracts from recent (2010-2016) national and 
international psychiatry and psychology conferences (American Psychological Association, American Psychiatric Association, National Education Association, International School Psychology Association, European Association of Counselling, and European Federation of Psychologists' Associations) were evaluated to identify unpublished studies. Endnote7 was used to import database search results and the results attained from hand search results to produce a list of all abstracts from retrieved studies. Duplicate results that were yielded from the various database and searches were removed and then abstracts of all remaining studies were reviewed.

\section{Study Inclusion Decision-Making}

The search strategy yielded 5,640 potentially relevant works. All of these were retrieved from the ERIC, PsycInfo, and Medline searches. No studies were yielded from a search of Cochrane Database of Systematic Reviews or from hand searches of 2010-2016 conference proceedings from American Psychological Association, American Psychiatric Association, National Education Association, International School Psychology Association, European Association of Counselling, or the European Federation of Psychologists' Associations.

\section{Selection and Coding of Studies}

Inclusion and exclusion decisions were based initially on a review of titles and abstracts by a single reader using a screening guide (see Table 1). The goal of this screening process was to rule out studies that did not meet eligibility criteria (i.e., studies that were not quantitative, did not sample children or adolescents, did not include both a measure of depression and a measure of academic achievement). Studies that could not be excluded definitively were retrieved in order for a full-text review, again using the 
screening guide, completed by a single screener. A second screener examined a random sample of $10 \%$ of the abstracts as a check of the reliability of the screening process.

Once a final list of studies which met all inclusion criteria was developed, relevant data from each included study was initially coded by a single reader using a coding guide developed for this project (See Table 2). This coding guide includes demographic information about participants and study design (sample size, time lapse between waves of data collection, etc.) as well as other variables (authors, publication year) and additional information related to study design and demographics. All study characteristics that were eventually used in analyses were coded by two researchers who worked independently. Disagreements were resolved in conference.

\section{Meta-Analytic Model Selection}

When designing a meta-analysis, a fixed effects model may be used when included studies are highly similar in design and sample characteristics. When included studies utilize dissimilar participants, or differing metrics or instruments are utilized to describe variables, a random effects model is more appropriate (Borenstein, Hedges, Higgins, \& Rothstein, 2009). Due to the wide variety of depression and achievement metrics, and differences among study participants and methodologies used, a random effects model was used in this study.

\section{Effect Size Calculation}

In order to explore the question of the impact of depression on subsequent achievement while controlling for initial levels of academic achievement, or the impact of achievement on subsequent depression while controlling for initial levels of depression, I first extracted the relevant correlations (i.e., the correlation between 
depression and achievement at time 1, the correlation between depression at time 1 and achievement at time 2, the correlation between achievement at time 1 and depression at time 2 , the correlation between achievement at time 1 and achievement at time 2 , and the correlation between depression at time 1 and depression at time 2). Then, the bivariate correlations listed above were used to simulate the underlying data structure (using R; R Development Core Team, 2013); this process was carried out 99 times for each study in a meta-analysis. The result was two important statistics for each meta-analysis: a mean standardized regression coefficient that describes the relationship between a T1 variable (e.g., academic achievement) and a T2 variable (e.g., depression) controlling for the baseline measure of the $\mathrm{T} 2$ variable (e.g., $\mathrm{T} 1$ depression), and the standard deviation of that distribution of standardized regression coefficients. The square of this standard deviation (i.e., the variance of the distribution of regression coefficients) was used to form the inverse variance meta-analytic weight.

\section{Moderator Analysis}

In order to determine whether the included studies were estimating the same population effect size, homogeneity analysis was undertaken. This study used the statistic Cochrane's $Q$, which tests for the presence of heterogeneity between studies. Cochrane's $Q$ is distributed as a chi-square statistic with degrees of freedom equal to the number of studies minus one. This statistic is calculated as:

$$
\mathrm{Q}=\Sigma w_{i}\left(E S_{i}-E S\right)^{2}
$$

in which the value $w_{i}$ represents the weight for the individual study, $E S_{i}$ is the mean effect size for study $i$, and $E S$ is the overall effect size for the included studies. Often, metaanalysts argue that a statistically significant $Q$ indicates there is sufficient heterogeneity 
in effect sizes to have warranted use of the random effects model and to evidence a need for analysis of moderator variables, though experts in meta-analysis often argue that model choice should be based on conceptual factors not empirical factors, as should the search for moderators (Huedo-Medina, Sánchez-Meca, Marín-Martínez, \& Botella, 2006); this is the approach I adopted. Moderator analysis was performed using analogs to multiple regression analysis and analysis of variance using the following study-level variables: (1) biological sex, operationalized as the percentage of female students in the sample, (2) age at baseline, operationalized as the average age listed for participants at the first wave of data collection, (or the grade level as represented by number added to the value 5.5 if grade level was provided rather than numerical age in samples), (3) lapse between first and final data waves (as measured in months), (4) measure of depression (coded as self-report or "other" report, and CDI vs. non-CDI, and (5) measure of achievement, operationalized as either GPA, standardized test, or "other". When studies provided achievement and depression data separately for female and male participants, these were treated as separate samples, thereby potentially allowing for finer-grained analysis of the role of biological sex as a moderator. When participant data was not broken down by biological sex, the percentage of female participants was used. The metafor package (Viechtbauer, 2010) of the R software program (R Development Core Team, 2013) was then utilized to perform a random-effects meta-regression, and to analyze the role of moderating variables biological sex, participant age, lapse between data waves, and the type of depression and achievement measures used in included studies.

\section{Funnel Plot and Trim and Fill Analyses}


In examining the effect sizes from each of the included studies, it is helpful to explore how studies with smaller samples impact the overall effect. In meta-analysis, weighting is used to prevent studies with smaller samples from contributing too much to the overall analysis, but this weighting does not ensure that small studies are not overly influencing the estimated effect size. Funnel plots provide a visual of how small study effects may potentially overinflate the overall effect size (Sterne, Higgins, \& Reeves, 2014). A funnel plot was developed to pictorially graph included studies' effect sizes (on the $\mathrm{x}$-axis) and standard error, a function of sample size (on the $y$-axis). Studies with smaller samples tend to result in more dispersed data points, while effect sizes for larger studies theoretically would tend to cluster closer to the overall effect size. The funnel plot can be symmetrical, indicating studies' effect sizes are dispersed uniformly, or asymmetrical with empty spaces, indicating possible presence of publication bias, heterogeneous samples, or chance (Mavridis \& Salanti, 2014).

To further examine how sensitive effects might be to publication bias, a trim and fill analysis was conducted to further analyze the potential impact of publication bias. Outlying, smaller studies which resulted in an asymmetrical funnel were removed, or "trimmed," from the funnel, and a new analysis was run to determine a more precise overall effect minus the trimmed studies, and then replacement values were "filled" back in to the funnel. The intention of the trim and fill procedure is to hopefully reduce outliers and create more precise estimates of effect and tighter confidence intervals around the overall effect size. This potentially yields a much higher proportion of correct estimates than if publication bias is not addressed (Taylor \& Tweedie, 1998). When studies were imputed to improve the symmetry of the funnel, the new overall effect size for any 
longitudinal relationship between achievement and depression might reflect a more precise point estimate. 


\section{CHAPTER III RESULTS}

The search strategies that I outlined in the Methods chapter identified a total of 5,640 abstracts. Abstract screening using the EndNote X7 program condensed the number of germane articles or papers (those meeting the inclusion criteria) to 520 . Nineteen articles were unavailable from the University of Louisville's interlibrary loan service (these were either unobtainable or required a fee to obtain) and/or could not be located online. Full-text screening to double check eligibility and to assess for the presence of correlation matrices revealed 26 studies, including 29 total independent samples on a total of 31,966 participants. These 26 studies were published or produced between 1998 and 2015, consisting of nine dissertations and 17 published studies.

Two studies provided separate estimates for reading and math achievement (Morales \& Guerra, 2016; Useche, 2016). Further review of these studies indicated that in each case, the reading and math samples were not independent of one another. (i.e., they were based on the same students). The bivariate correlations garnered from each sample (time one depression to time two depression, time one depression to time two achievement, time one achievement to time two achievement, time one achievement to time two depression, time one achievement and time one depression) samples were therefore averaged into one composite for each study. The composites were transformed using the Fisher's $z$ transformation prior to being averaged, then the inverse of each study's Fisher's $z$ transformed composite was used in the analysis. 


\section{The Relationship between Depression and Subsequent Achievement}

Results from utilization of the statistical bootstrapping technique on effect sizes from depression at baseline and subsequent achievement in the samples (while controlling for achievement at baseline) indicate that this longitudinal relationship is not statistically significant. The overall effect size was $r=-.024$, with a standard error of .021 and a $95 \%$ confidence interval of -0.0661 to 0.017 .

With regard to the homogeneity in the 29 samples, after bootstrapping was used to analyze the depression to achievement path, the resulting $Q(28)=198.4, p<.001$ is statistically significant and indicates that there is substantially more variability in effect sizes than would be predicted by chance alone. The $I^{2}$ statistic, which represents the proportion of total heterogeneity to of the amount effect size variability that is due to true between study variability (as opposed to sampling error) for the depression to achievement path, was $94 \%$, indicating that the variability between included studies is due to heterogeneity rather than just chance. This means that a relatively large portion of the variance in effect sizes appears to be related to real differences among studies.

I conducted moderator analyses to explore the impact of baseline participant age, lapse between first and final data waves, and achievement and depression measures. None of these variables moderated the relationship between depression and subsequent achievement. Table 1 includes these moderator values from each of the studies included in the current analysis.

The baseline range of ages of participants in the current meta-analysis ranged from 5.5 to 18 , with an average of 10.65 . Age at baseline was not a statistically 
significant moderator of depression and subsequent achievement, $(r=0.006, S E 0.008, p$ $=0.42$ ). The $95 \%$ confidence interval for this effect estimate was -0.009 to 0.021 .

Percentage of female participants of all 29 samples was examined to see whether biological sex moderated the relationship between depression and subsequent achievement. This was not a statistically significant moderator, with $r=0.001, p=.183$. The $95 \%$ confidence interval for this effect estimate was -0.0006 to 0.029 .

Lapse between data waves was not a statistically significant moderator of the relationship between depression and subsequent achievement, with $r=-0.007, p=0.495$ and a standard error of 0.046 . The $95 \%$ confidence interval for this effect estimate was 0.04 to 0.026 .

After studies were evaluated for the specific means by which each measured achievement, it became apparent that the most common measure of achievement used was GPA, as reported by student, parent, or through school records. I made the decision to compare the effects from those studies utilizing GPA against effects sizes yielded from studies using some other measure of achievement. Those studies utilizing GPA $(\mathrm{k}=19)$ were coded as a 1 and compared with those studies using other means of measuring achievement $(\mathrm{k}=7)$, which was coded as a 0 . Type of achievement measure did not moderate the relationship between depression and subsequent achievement, with $r=$ 0.037 (SE 0.046), $p=0.42$. The $95 \%$ confidence interval for this effect estimate was 0.052 to 0.126 .

After evaluating the included studies to determine the specific means by which each had measured depression, two issues were apparent. First, the Children's Depression Inventory (CDI) was the most commonly utilized measure in the included studies. 
Second, the number studies utilizing a self-rating compared with those utilizing rating from "other" informants was sufficient to constitute an adequate moderator analysis of the role of informant. To assess the extent to which measurement of depression was related to effect sizes, I therefore decided to conduct two sub-analyses to explore not only the source of depression data but the commonly utilized CDI versus other measures. Source of depression data, defined here as studies utilizing self-report $(\mathrm{k}=20)$ was coded as a 1 and compared with those studies utilizing reports from others $(k=5)$, which were coded as a 0 . Source of depression data was not a statistically significant moderator of the relationship between depression and subsequent achievement, with $r=-0.005$ (SE 0.038), $p=0.89$. The $95 \%$ confidence interval for this effect estimate was -0.080 to 0.070 .

Effect sizes from those samples utilizing the CDI $(\mathrm{k}=20)$ were coded as a 0 and compared with those using some other measure $(\mathrm{k}=9)$, coded as a 1 . I found that relative to other measures, use of the CDI did not statistically significantly moderate the relationship between depression and subsequent achievement, with $r=0.07$ (SE 0.045), $p$ $=0.12$. The $95 \%$ confidence interval for this effect estimate was -0.019 to 0.157 .

Effect sizes and standard errors from published studies $(\mathrm{k}=17)$ were compared with those from unpublished dissertations $(\mathrm{k}=9)$ to examine for the presence of publication bias. A funnel plot was developed to pictorially graph included studies' effect sizes (on the x-axis) and standard error, a function of sample size, on the y-axis. This funnel plot is available in Figure 3. I conducted a trim and fill analysis to further explore how sensitive the effects were to possible publication bias. Results of the trim and fill analysis are available in Table 9. With six studies imputed from the right of the mean, the 
trim and fill analysis indicated that the resulting modified effect size of 0.008 (SE 0.022) was not very different than the originally derived effect.

\section{The Relationship Between Achievement and Subsequent Depression}

Results from utilization of the statistical bootstrapping technique on effect sizes from achievement at baseline and subsequent depression in the 29 included samples (while controlling for depression at baseline) indicate that this longitudinal relationship is statistically significant. The overall effect size was $r=-.082, p<.0001$, with a $95 \%$ confidence interval of -0.1171 to -0.0478 . With regard to the homogeneity in the 29 samples, after bootstrapping was used to analyze the achievement to depression path, the resulting $Q(28)=149.1, p<.001$ is both statistically significant and indicates that there is substantially more variability in effect sizes than would be expected by chance alone. The $I^{2}$ statistic, representing total heterogeneity to the proportion of effect size variability that is due to true between study variability (as opposed to sampling error) for the achievement to depression path, was $87 \%$. This indicates that a relatively large portion of the variance in effect sizes appears to be related to real differences among studies, rather than just chance.

I conducted moderator analyses to explore the impact of baseline participant age, lapse between first and final data waves, and achievement and depression measures. None of these variables moderated the relationship between achievement and subsequent depression. Age at baseline was not a statistically significant moderator of depression and subsequent achievement, with $r=0.004$ (SE 0.006), $p=0.489$. The $95 \%$ confidence interval for this effect estimate was -0.008 to 0.016 . 
Percentage of female participants of all 29 samples was examined to see whether biological sex moderated the relationship between achievement and subsequent depression. This was not a statistically significant moderator, with $r=-0.0002$ (SE $0.0008), p=0.81)$. The $95 \%$ confidence interval for this effect estimate was -0.018 to 0.001 .

Lapse between data waves was not a statistically significant moderator of the relationship between achievement and subsequent depression, with $r=0.001$ (SE $0.0014), p=0.49$. The $95 \%$ confidence interval for this effect estimate was -0.002 to 0.004 .

Type of achievement measure, defined here as studies utilizing GPA $(\mathrm{k}=19)$ compared with those studies using other means of measuring achievement $(\mathrm{k}=7)$, did not moderate the relationship between achievement and subsequent depression, with $r=0.01$ (SE 0.037), $p=0.80$. The $95 \%$ confidence interval for this effect estimate was -0.064 to 0.083 .

To explore the impact of depression measure on the relationship between achievement and subsequent depression, I conducted two sub-analyses: one exploring the source of depression data (self vs. other), and the comparing those studies using the CDI versus those studies which used a different depression measure. Source of depression data, defined here as studies utilizing self-report $(\mathrm{k}=20)$ compared with those studies utilizing reports from others $(\mathrm{k}=5)$, was not a statistically significant moderator of the relationship between achievement and subsequent depression, with $r=-0.034$ (SE 0.045), $p=0.45$. The $95 \%$ confidence interval for this effect estimate was -0.1219 to 0.054. Effect sizes from those samples utilizing the CDI $(k=20)$ compared with those 
using some other measure $(\mathrm{k}=9)$ indicate that the use of the CDI was not a statistically significant moderator of the relationship between achievement and subsequent depression, with $r=0.006$ (SE 0.039), $p=0.89$. The $95 \%$ confidence interval for this effect estimate was -0.071 to 0.082 .

Effect sizes and standard errors from published studies $(\mathrm{k}=17)$ were compared with those from unpublished dissertations $(\mathrm{k}=9)$ to examine for the presence of publication bias. I conducted a trim and fill analysis to further explore how sensitive the effects were to possible publication bias. Results of the trim and fill analysis are available in Table 9. With five studies imputed from the left of the mean, the trim and fill analysis indicated that the resulting modified effect size of -0.102 (SE 0.018) was statistically significant, although not very different from the originally derived effect size of -0.0824 . 


\section{CHAPTER IV DISCUSSION}

While a negative, cross-sectional association between depression and achievement among adolescents has been demonstrated (Bardone et al., 1996; Bernstein et al., 1991; Kovacs et al., 1998; Quiroga et al., 2013; Fröjd et al., 2008) the magnitude and directionality of the relationship between achievement and depression over time remained the subject of some debate. Thus, the purpose of the current study was to clarify the directionality and strength of the relationship between depression and achievement based on multiple time points at which both are measured, and to elucidate the role of moderator variables to increase the understanding of for whom this interrelationship may be strongest. In order to yield this information, I completed two separate meta-analyses: one related to the impact of depression on subsequent achievement and the other related to the impact of achievement on subsequent depression. I hypothesized that there would be statistically significant, negative correlation between achievement and subsequent depression controlling for baseline depression, and depression and subsequent achievement.

After an exhaustive literature search, studies included in the analyses were comprised of 30,966 participants in 26 different studies and a total of 29 samples. First, regarding the path from depression to subsequent achievement, I found that this relationship was not statistically significant. Practically speaking, the presence of depressive symptomology was not correlated with future academic achievement. When I combined studies for the current analysis I found the relationship between depression and subsequent achievement 
was not statistically significant once baseline achievement was accounted for. It is worth noting that baseline achievement was highly correlated with later achievement with a correlation of .73 , which resulted in much less variability in achievement at the final data wave which could be possibly explained or predicted by depression. In essence, if achievement is the best predictor of future achievement, it becomes more difficult to evidence a statistically significant relationship with any other predictor variable when controlling for baseline achievement.

These results indicating that depression is not a statistically significant predictor of later achievement are in line with the results from several previous studies that yielded no statistically significant relationship between depression and subsequent achievement (Breslau et al., 1998; Cole et al, 1996; Hanson et al., 2004; Miech et al., 1999; Patterson et al., 1991). While symptoms of depression include poor concentration (APA, 2015), and negative affect, which is negatively correlated with concentration and performance on memory-related tasks (Dux et al., 2008) and cognitive tasks (Kaslow et al., 1984), it does not seem that depressive symptoms predict achievement problems based on the results of my analysis. There are several possible explanations for this finding.

First, moderating variables such as biological sex, learning disabilities, and the presence of comorbid disorders might impact the magnitude of the relationship between depression and subsequent achievement. Verboom, Sijtsema, Verhulst, Penninx, \& Ormel, (2014) found that biological sex plays a role in the causal relationship between depression and subsequent achievement. These authors found only for girls but not for boys a statistically significant relationship. Boys typically exhibit a stronger relationship between externalizing problems and subsequent academic achievement than girls 
(Duncan et al., 2007; McCarty et al., 2008), indicating that perhaps the types of psychological symptom burdens which might precede academic issues are somewhat predicted by biological sex. If indeed females are more likely to exhibit achievement problems after depression, then it is possible the current analysis did not include enough all-female samples to pick up on this potentially significant relationship among females. For both males and females, there is evidence that, in the presence of additional comorbid psychopathology or learning disability, depression may be correlated with subsequent achievement issues (Breslau et al., 1998; Heath \& Ross, 2000). Assessment for internalizing disorders (not just depression) as predictors of achievement problems may allow for more effective identification of children and adolescents dealing with multiple diagnoses, potentially reducing the chances of subsequent achievement problems.

Whether a child faces adverse life events, and what type of support and abilities they possess, may bear impacts on why depressive symptoms do not necessarily lead to achievement problems. First, ability or a sense of competency in one arena (such as school performance) might lead to positive affect in general and about one's self (Bandura, 1977; White, Moffitt, \& Silva, 1989), conceivably preventing mental health problems. In other words, academic achievement is not necessarily impacted by depressive symptoms. This hypothesis is supported by findings (Moon, Kwon, \& Chung, 2015) demonstrating that academic resiliency buffers students from the effects of their depression. Adverse life experiences during childhood are associated with future achievement problems, and the presence of depressive symptoms moderates the relationship between these negative events and future school issues (Miech et al., 1999). Masten et al. (1999) found that better intellectual functioning and parenting resources 
enhance students' resiliency and competence and are associated with improved outcomes across developmental domains (including the academic domain), even in the presence of severe adversity. Essentially, when facing difficult circumstances, having supportive caregivers and a high IQ buffers the negative effect of adversity on a child's academic achievement. Future research might examine whether those children who experience less parental support do in fact exhibit significant achievement problems after experiencing depression.

With regard to the relationship between achievement and subsequent depression, I found a small, but statistically significant, negative relationship between these two variables. While the relationship between depression and subsequent achievement was not statistically significant, problems with achievement are associated with emergence of depressive symptoms at a later time. These results are in line with those reported by Huang (2015) and support the cascading effects model proposed by Masten et al. (2005). This statistically significant connection between achievement and subsequent depression also supports the response styles theory of depression (Nolen-Hoeksema, 1991) as well as the competency model described by Cole (1991). It appears that issues in the academic sphere have implications for a child's mental health. Based on these results, I feel it is important for teachers to be aware of potential mental health effects that might encumber those students who receive low grades, so that future depressive issues can be proactively addressed. Perhaps when grades begin to drop, support for both academic achievement and mental health can be offered. This could manifest in the form of automatic referrals to counseling staff when students appear to suffer academically, in addition to providing 
psycho-education to caregivers related to the possible mental health implications of decreasing academic performance.

\section{Moderator Variables}

There was substantial variability observed between the samples included in the current analysis for both longitudinal paths between achievement and depression, which suggests that other variables likely impact the relationship. Despite this variability, however, none of the moderator variables had statistically significant impacts on the longitudinal relationships between achievement and depression. This lack of an interaction effect for either path between achievement and depression could be due to a number of factors. The upper bounds of confidence intervals around yielded moderator

effects can sometimes represent how these real-world moderation effects might manifest. Indeed, I examined confidence intervals around the yielded moderator effect sizes to explore whether any of these moderators might be nearing either statistical or practical significance; none appeared to be clinically significant. This indicates that these moderator variables weren't found to have sufficient impact on the relationships between achievement and depression so as to be detectable in practice. Even those upper bounds of confidence intervals that neared significance represented such small effects that any practical effects would be negligible.

The lack of a moderating effect of baseline age, lapse between data waves, biological sex, or depression/achievement measures might also indicate that there were not enough studies, or low power, in each of these analyses. Initially, I had hoped to find at least 18 samples to provide enough data for an adequate meta-analytic comparison (Valentine et al., 2010). In the end, I was able to locate 26 studies (29 samples), which 
should indicate ample data to meet this threshold. However, the number of studies and participants that I was able to compare at the moderator level was significantly fewer than the 26 studies examined for overall analyses. Thus, the low number of samples is another possible explanation for my not finding a statistically significant moderating effect of baseline age, lapse between data waves, biological sex, or depression and achievement measures. For example, all female or all male samples were not common in my literature search, which meant I utilized percentage female to describe the role of biological sex in the longitudinal relationship between achievement and depression. Similarly, there was not enough variety in depression measures or achievement measures to allow for any potential effects to be detected. Future studies which examine achievement and depression might provide additional data points needed to allow for such comparisons. Other possible explanations for the lack of statistically significant effects of specific moderators are discussed below.

The age of participants at baseline was not statistically significantly associated with the longitudinal correlation between achievement and depression in the current meta-analysis. Baseline ages were relatively well-dispersed from 5.5 to 18 years, with an average baseline age of 11.5 years. This wide dispersion allowed me to treat age as a continuous variable in the moderator analysis, and therefore a surer interpretation of this moderator analysis' results. While I hypothesized that younger children would evidence stronger correlations for both longitudinal paths based on previous research (Herman et al., 2007; Rudolph et al., 2001; Topitzes et al., 2009), this was not the case for either achievement and subsequent depression or depression and subsequent achievement. Thus, my results are contrary to my hypotheses and those suggested by Cole's 
competency model (1997) which describes younger children as being more influenced by the evaluative feedback of teachers and caregivers than older adolescents. Depression was predicted by achievement problems consistently throughout the childhood and adolescent years.

The length of time elapsed from the date of first wave of data collection until the final data collection did not statistically significantly moderate the longitudinal relationships between achievement and depression. This seems contrary to Huang (2015) who found that as the lapse between data waves increased, the correlation between achievement and subsequent depression decreased. However, while the average span from first data wave to final data wave was 24.5 months, with a range from 6 to 60.2 months in my meta-analysis, the lapse between data waves in Huang's meta-analysis was up to 19 years. Thus, it might be that the association between achievement and depression decreases until it reaches a point where the association is not statistically significant. This hypothesis would be supported by Masten et al. (2005) who found no statistically significant correlation between depression and subsequent achievement in their study with time lags of 7, 10, and 25 years. Perhaps in the shorter period of time (6 years or less in the current meta-analysis), a child is likely still enrolled within one school (i.e., has not transitioned to the next level of school) and therefore school environment effects (like grades) are more salient than for a child who has developed in ten years since their depression and school data was gathered. To test this hypothesis, future research might allow for measurement of depression and achievement at more regular intervals, particularly upon entry to and exit from a particular school level, to see when the correlations between achievement and depression are most pronounced. 
Based on my search for studies that met my inclusion criteria, there were not enough samples utilizing the same depression measures to compare various measures to one another. However, I was able to compare CDI vs. non-CDI studies. I found that type of measure of depression did not moderate the relationship between achievement and subsequent depression, or depression and subsequent achievement, which is consistent with the results found in Huang's 2015 meta-analysis of achievement and subsequent depression. Of the 26 included studies, six utilized the CDI. CDI versus non-CDI study analysis indicated that this distinction was not a statistically significant moderator of the relationship between achievement and subsequent depression or depression and subsequent achievement.

To further explore how method of depression measurement might impact the longitudinal relationship between achievement and depression, I considered whether the source of depression data (self or other) might impact the longitudinal relationship between achievement and depression; it was not a statistically significant moderator of either path. As The CES-D, CDI, and BDI-II are highly correlated with other common measures of depressive symptomology (Brooks \& Kutcher, 2001; Myers \& Winter, 2002), it makes sense that their differing impact on the longitudinal relationship between achievement and depression might not be substantial.

Type of achievement measure (GPA versus standardized test) was not a statistically significant moderator of the longitudinal relationship between achievement and depression. Dickinson et al. (2016) reported that GPA and standardized tests (single administration) may measure decidedly different aspects of performance, with standardized tests designed to measure specific learning content, while GPA allowing 
more flexibility for subjective analysis and rating of the grader (Guskey, 2000). In addition, self-reported GPAs may not be entirely accurate, with variation in accuracy being based on performance, indicating students are more likely to report good grades than true grades (Kuncel, Crede, \& Thomas, 2005). An additional consideration here is that achievement measures cannot necessarily be used interchangeably, as different measures correlate to other educational or psychological constructs in distinct ways (Dickinson et al., 2016). While Roorda et al. (2011) found that achievement measure (in that study, GPA versus test scores) did impact cross-sectional correlations between achievement and psychological constructs, in the current analysis, this was not the case. Future research which examines the relationships between depression and achievement could contribute a more exhaustive exploration of this nuanced difference by measuring both GPA and standardized testing results to help discern the potential different presentation or correlations between the two measurements.

Regarding the role of biological sex as a moderator in the longitudinal relationships between achievement and depression in the 26 included studies, I did not find enough studies to adequately make a comparison between male and female participants. Two studies included only female participants, (Mikami \& Hinshaw, 2006; Trost \& el-Khouri, 2008), and two studies offered separate effect sizes for male vs. female participants (Colarossi, 2000; Cunningham, 2009). The remaining 22 studies offered "percentage female" to describe their participant demographics where biological sex is concerned. This dearth of samples broken down by biological sex (or studies examining these constructs for separate male and female samples) is unfortunate, as targeting the conditions and demographics most susceptible to the progressions between 
depressive and academic problems may allow for quicker and more effective relief of issues in either or both areas of a child's life.

\section{Limitations of the Current Meta-Analysis}

I began the current meta-analysis with the intention of providing a comprehensive and exhaustive review of studies which examined achievement and depression. I made efforts to access literature and research beyond the areas of mental health and education by using the Medline database (as well as PsycInfo and ERIC), in addition to searching the conference proceedings of several professional organizations. I consulted with practitioners and researchers in the field of mental health and education measurement to develop appropriate search terms. However, the search criteria and methods I used may have still allowed for some studies to escape the literature, conference, and dissertation/theses searches I performed. Further, any studies which have been published or completed since the searches were performed in January 2016 for the current study would not have been included.

Heterogeneity testing of included studies indicated that the studies differed in methodology, sample characteristics, study lengths, and a number of other different characteristics. I hoped that by combining every study that I could access through a careful search, eventually any real effects would be detected. The validity of my results depends on those included studies being undertaken with integrity and accurately reflecting the characteristics of their respective samples. The results yielded from the current meta-analysis are only as valid as the studies that were combined to yield metaeffects. While many cross-sectional studies found contrary results, when combined, statistically significant overall effects (for the achievement to depression path) were detected. So, regardless of any differences in methodology or quality, the results found 
here cannot be attributed to chance and should be regarded as meaningful and significant. Further, while ten percent of the yielded abstracts were double reviewed to ensure that inclusion decisions were reliable, further review of abstracts by a second coder may have enhanced the reliability of inclusion decisions and therefore strengthened the inferences which can be made from yielded results. Finally, while I was able to combine enough studies to make an adequate analysis of overall effects, the number of studies and participants that I was able to compare at the moderator level did not allow for as thorough an examination of moderating variables as I had hoped to undertake. For example, overwhelmingly, studies combined data for male and female participants, with only six of the 29 samples broken down into either all female or all male data. This prevented the more in-depth examination of how biological sex impacts the relationship between achievement and depression. I am hopeful that future studies which examine achievement and depression might provide the data points needed to analyze moderation effects with more precise estimates.

In my literature search, I encountered a number of studies whose abstracts alluded to measurement of depression or achievement, but upon further review these did not provide adequate assessment of achievement or depressive symptoms to meet my inclusion criteria. Studies in which participants might be asked a question about sad mood, but not given further assessment were not included. Further, studies which measured achievement and depression at multiple time points, but could not provide correlations for achievement and depression measured at the same data wave were excluded. Therefore, I might not have captured every study that examined achievement and depression longitudinally. Those that I did include, however, each used a sufficiently 
valid measurement of achievement and depression to contribute to the meta-analyses. Additionally, after I reviewed abstracts in the initial stages of these meta-analyses, 19 studies were unavailable due to either all search resources being exhausted or the University of Louisville Library being unable to procure the studies free of charge. While I cannot be sure that these studies would have included the data required for inclusion in these meta-analyses, I am unable to confirm that they would not have been appropriate for inclusion.

\section{Areas for Future Research}

The relatively small number of samples in which achievement measures (GPA versus test scores) were compared suggests that future studies examining achievement might also include test scores and GPA or grades. Using both types of metrics to measure achievement would then allow for enhanced comparison to examine whether they both assess the construct of achievement in the same manner, and are answering the same questions. This may help to reduce the chance that a moderating effect of achievement measure is missed. Regarding the moderating variable of depression measure, the current meta-analysis's inclusion criteria yielded too few studies to run a robust comparison between various measures for depression. Future studies which can undertake more nuanced analysis of depression measure (comparing measures beyond CDI vs. non-CDI), might indicate a statistically significant effect for depression measure. Perhaps future studies examining depression and achievement might also utilize clinical interviews as a means for measuring depression, as none of the studies which met the current study's inclusion criteria utilized this type of depression measure. Although clinical interviews can be more expensive and time-intensive to conduct, relative to self-reports such as the 
$\mathrm{CDI}$ or BDI, the structured clinical interview provides superior diagnostic accuracy and is considered the "gold standard for a research diagnosis of depression" (Cohen, 1998). Structured interviews as a means for assessing for depression would allow for more accurate identification of depressed individuals in future studies, even among novice interviewers (Ventura, Liberman, \& Green, 1998).

An exhaustive literature search did not identify a sufficient number of articles to evaluate whether biological sex impacts the longitudinal relationship between achievement and depression. Future research is needed to address the role of biological sex in moderating the longitudinal relationship between achievement and depression. While a few primary studies reported a moderating effect of biological sex on the relationships between achievement and depression (Derdikmon-Eiron et al., 2001; Herman et al., 2008; McCarty et al., 2008; Needham, 2009), there are other longitudinal results that did not yield a moderating effect of biological sex (Colarossi, 2000; Latendresse, 2004). The dearth of samples broken down by biological sex for the current study and contrary results from cross-sectional and longitudinal studies indicate a need for further exploration of biological sex as a moderator of these two constructs over time. Initially, I made the decision to only include studies which provided effect sizes between multiple time points based on the same participants, thereby hopefully reducing sampling error and allowing for stronger inferences about effects (Diggle, Liang, \& Zeger, 1994). In the future, an analysis which includes primary studies which examined either, but not necessarily both, paths between achievement and depression over time could be undertaken to see if effects are different from those found in the current study. As the number of included studies here was reduced greatly by the requirements that both 
achievement and depression had to be measured at least twice, future analyses (of both longitudinal paths between depression and achievement) which do not require multiple time points for both depression and achievement might then allow for the inclusion of many more participants. While assessing the same participants for depression and achievement on multiple occasions might conceivably reduce sampling error, requiring only one longitudinal path between achievement and depression might open up the pool of includable studies to many other studies or publicly available data sets in which only one path is measured. More includable studies results lead to more data-points for future meta-analyses, and more data points theoretically will lead to more precise estimates of effects (Lakens, Hilgard, \& Staaks, 2016).

I also included a requirement that included studies must have incorporated a correlation matrix. My reason for the decision to include this specific criterion was to reduce outcome reporting bias by including studies beyond those in which yielded correlations are statistically significant or supporting the researchers' hypotheses (Higgins \& Green, 2009). Inclusion of a correlation matrix often yields more effects than those found to be statistically significant. Therefore, one of my goals of this metaanalysis was to include as many correlations from previous studies as possible, including those that did not indicate an expected relationship between depression and achievement, or those results which may not have been previously published. Future analyses could compare results yielded from studies with correlation matrices with those studies that only report specific statistics in the text. If any difference is found, it might indicate that indeed, some outcome reporting bias exists, with the implication that inclusion of a 
correlation matrix enhances the likelihood that statistically significant and non-significant results will be reported.

\section{Implications for Practice}

With the results of the current analyses in mind, there are several ways in which practice might be enhanced to address the needs of children and adolescents. The results that academic achievement and subsequent depression are negatively correlated will hopefully spark targeted prevention programming toward those individuals most in need. While a causal relationship cannot be implied because a third variable confounding the relationships between achievement and depression cannot be ruled out, these results do indicate a need for action when grades academic performance begins to suffer. Further, the third variable most likely impacting a relationship between achievement and subsequent depression is prior baseline achievement, which was controlled for through the use of partial correlations. While the negative effect of achievement on subsequent depression found here indicates a statistically significant but weak relationship, when bearing in mind the cascading effects described by Masten et al. (2005), problems in one domain of functioning may impact other areas of functioning and can have a larger, potentially cumulative effects. It therefore behooves practitioners to heed the results found here, and to intervene when academic performance signals a problem. Several ideas for how this might look in practice are suggested, including an automatic referral system, universal screening, and interdisciplinary treatment team support.

First, automatic referrals to school counseling staff after a student's grades

decrease might be one avenue for addressing the mental health implications of poor academic performance. Further, efforts to increase the effective identification of students 
suffering academically as well as with mental health issues might benefit schools. For example, according to the Suicide Prevention Research Center's "The Role of Teachers in Preventing Suicide," (2012), universal screening for suicidality is undertaken in many middle and high school districts in the United States during each September, which is Suicide Awareness Month. Results which indicate that a student may be at risk for suicide can (with the student's permission) be shared with school counseling personnel. There is evidence that while many students will be identified through such universal measures, gatekeepers such as teachers are needed to enhance the likelihood that depressed students are identified, in addition to routine record review to see if behavioral or emotional problems have been observed in the school setting (Scott et al., 2010). An interdisciplinary treatment team approach, in which stakeholders interested in the wellbeing of a child (teachers, counselors, caregivers) can work together to provide support across domains, might be useful in the school setting to address the needs of students whose grades begin to drop. My results provide further empirical support to the idea that school personnel crossing disciplinary lines to support children across multiple domains in one area may enhance their success in multiple domains down the road. Further, moderator analyses here indicated that the connection between academics and future mental health is statistically significant for children at all levels of schooling. This indicates that school personnel in primary, middle, and high schools should concern themselves with the mental health of their students in order to enhance mental health outcomes for students in the future.

In closing, the small but statistically significant correlation between achievement and subsequent depression indicate that difficulties in the classroom have implications 
beyond the school setting. My results lend empirical support to interventions that cross disciplinary lines and see the child or adolescent as more than just a therapy client or student, but an individual whose needs in one area overlap with their needs in others. For example, depression is listed as a type of Emotional Disturbance which may qualify a student for either specialized instruction or accommodations as part of Individualized Education Plan or 504 plan in schools. My results indicate that, across the school age years, whether academic success is measured by standardized tests or grades, the academic performance of a child today bears an impact on their mental health in the future. 


\section{REFERENCES}

Abramson, L. Y., Seligman, M. E., \& Teasdale, J. D. (1978). Learned helplessness in humans: Critique and reformulation. Journal of Abnormal Psychology, 87, 49.

Achenbach, T. M., Dumenci, L., \& Rescorla, L. A. (2003). DSM-Oriented and Empirically Based Approaches to Constructing Scales from the Same Item Pools. Journal Of Clinical Child And Adolescent Psychology, 32, 328-340. doi:10.1207/S15374424JCCP3203_02

Achenbach, T. M., \& Rescorla, L. A. (2004). The Achenbach System of Empirically Based Assessment (ASEBA) for Ages 1.5 to 18 Years. In M. E. Maruish, M. E. Maruish (Eds.), The use of psychological testing for treatment planning and outcomes assessment: Instruments for children and adolescents, Volume 2, 3rd ed (pp. 179-213). Mahwah, NJ, US: Lawrence Erlbaum Associates Publishers.

American Psychiatric Association. (2013). Diagnostic and statistical manual of mental disorders (5th ed.). Arlington, VA: American Psychiatric Publishing.

Angold, A., \& Costello, E. J. (1993). Depressive comorbidity in children and adolescents: Empirical, theoretical, and methodological issues. The American Journal of Psychiatry, 150, 1779-1791. doi:10.1176/ajp.150.12.1779

Bandura A. (1977). Self-efficacy: toward a unifying theory of behavioral change. Psychological Review, 84, 191-215.

Bardone, A. M., Moffitt, T., Caspi, A., \& Dickson, N. (1996). Adult mental health and social outcomes of adolescent girls with depression and conduct disorder.

Development and Psychopathology, 8, 811-829. doi:10.1017/S0954579400007446

Beck, A., Steer, R., \& Brown, G. (1996). Beck Depression Inventory-Second Edition. Manual. San Antonio, TX: The Psychological Corporation.

Berndt, E. R., Koran, L. M., Finkelstein, S. N., Gelenberg, A. J., Kornstein, S. G., Miller, I. M., \& ... Keller, M. B. (2000). Lost human capital from early-onset chronic depression. American Journal of Psychiatry, 157, 940-947. doi:10.1176/appi.ajp.157.6.940 
Bernstein, G. A., \& Borchardt, C. M. (1991). Anxiety disorders of childhood and adolescence: A critical review. Journal of the American Academy of Child \& Adolescent Psychiatry, 30, 519-532. doi:10.1097/00004583-199107000-00001

Borenstein, M., Hedges, L., Higgins, J., \& Rothstein, H. R. (2009). Introduction to metaanalysis. Chichester, West Sussex: Wiley.

Breslau, J., Lane, M., Sampson, N., \& Kessler, R. C. (2008). Mental disorders and subsequent educational attainment in a US national sample. Journal of Psychiatric Research, 42, 708-716. doi:10.1016/j.jpsychires.2008.01.016

Brooks, S. J., \& Kutcher, S. (2001). Diagnosis and measurement of adolescent depression: A review of commonly utilized instruments. Journal of Child and Adolescent Psychopharmacology, 11, 341-376. doi:10.1089/104454601317261546

Chang, E. S., Greenberger, E., Chen, C., Heckhausen, J., \& Farruggia, S. P. (2010). Nonparental adults as social resources in the transition to adulthood. Journal of Research on Adolescence, 20, 1065-1082. doi:10.1111/j.1532-7795.2010.00662.x

Chen, H. (2010). Robust protective factors that help youths with a parent experiencing depression achieve positive adjustment. (Unpublished doctoral dissertation). Virginia Commonwealth University, Richmond, VA.

Chen, X., Yang, F., \& Wang, L. (2013). Relations between shyness-sensitivity and internalizing problems in Chinese children: Moderating effects of academic achievement. Journal of Abnormal Child Psychology, 41, 825-836. doi:10.1007/s10802-012-9708-6

Cohen, S. (1998). John D. and Katherine T. MacArthur Foundation Research Network on SES \& Health: Measures of Depression as a Clinical Disorder. Retrieved from http://www.macses.ucsf.edu/research/psychosocial/depression.php .

Colarossi, L. G. (2000, August). Gender differences in social support from parents, teachers, and peers: Implications for adolescent development. (Unpublished doctoral dissertation). University of Michigan, Ann Arbor, MI.

Cole, D. A. (1991). Preliminary support for a competency-based model of depression in children. Journal of Abnormal Psychology, 100, 181-190. doi:10.1037/0021843X.100.2.181 
Cole, D. A., Jacquez, F. M., \& Maschman, T. L. (2001). Social origins of depressive cognitions: A longitudinal study of self-perceived competence in children. Cognitive Therapy and Research, 25, 377-395. doi:10.1023/A:1005582419077

Cole, D. A., Martin, J. M., \& Powers, B. (1997). A Competency-based Model of Child Depression: A Longitudinal Study of Peer, Parent, Teacher, and Self-evaluations. Journal of Child Psychology and Psychiatry, 38, 505-514. doi:10.1111/j.14697610.1997.tb01537.x

Cole, D. A., Martin, J. M., Powers, B., \& Truglio, R. (1996). Modeling causal relations between academic and social competence and depression: A multitrait, multimethod longitudinal study of children. Journal of Abnormal Psychology, 105, 258-270.

Cooley, C. H. (1902). Human nature and the social order. New York: Scribner.

Cunningham, J. N., Kliewer, W., \& Garner, P. W. (2009). Emotion socialization, child emotion understanding and regulation, and adjustment in urban African American families: Differential associations across child gender. Development and Psychopathology, 21, 261-283. doi:10.1017/S0954579409000157

Cytryn, L., McKnew, D. H., \& Bunney, W. E. (1980). Diagnosis of depression in children: A reassessment. The American Journal of Psychiatry, 137, 22-25. doi:10.1176/ajp.137.1.22

D’Agostino, J. V., \& Powers, S. J. (2009). Predicting teacher performance with test scores and grade point average: A meta-analysis. American Educational Research Journal, 46, 146-182. doi:10.3102/0002831208323280

Denault, A., Poulin, F., \& Pedersen, S. (2009). Intensity of participation in organized youth activities during the high school years: Longitudinal associations with adjustment. Applied Developmental Science, 13, 74-87. doi:10.1080/10888690902801459

Derdikman-Eiron, R., Indredavik, M. S., Bakken, I. J., Bratberg, G. H., Hjemdal, O., \& Colton, M. (2012). Gender differences in psychosocial functioning of adolescents with symptoms of anxiety and depression: Longitudinal findings from the NordTrøndelag Health Study. Social Psychiatry and Psychiatric Epidemiology, 47, 1855-1863. doi:10.1007/s00127-012-0492-y

Dickinson, E. R., \& Adelson, J. L. (2016). Choosing among multiple achievement measures: Applying multitrait-multimethod confirmatory factor analysis to measures of state assessment, ACT, and student GPA data. Journal of Advanced Academics, 27, 4-22. doi: 10.1177/1932202X15621905 
Diggle, P., Liang, K., \& Zeger, S. Analysis of Longitudinal Data. Oxford, United Kingdom: Oxford University Press, 1994.

Duncan, G., Dowsett, C., Claessens, A., Magnuson, K., Huston, A., Klebanov, P, ... Japel, C. (2007). School readiness and later achievement. Developmental Psychology, 43, 1428-46. doi: 10.1037/0012-1649.43.6.1428

Dux, M. C., Woodard, J. L., Calamari, J. E., Messina, M., Arora, S., Chik, H., \& Pontarelli, N. (2008). The moderating role of negative affect on objective verbal memory performance and subjective memory complaints in healthy older adults. Journal of the International Neuropsychological Society, 14, 327-336. doi: $10.1017 / \mathrm{S} 1355617708080363$

Fauber, R., Forehand, R., Long, N., Burke, M., \& Faust, J. (1987). The relationship of young adolescent Children's Depression Inventory (CDI) scores to their social and cognitive functioning. Journal of Psychopathology and Behavioral Assessment, 9 , 161-172. doi:10.1007/BF00960572

Feshbach, N. D., \& Feshbach, S. (1987). Affective processes and academic achievement. Child Development, 58, 1335-1347. doi:10.2307/1130625

Fletcher, J. M. (2010). Adolescent depression and educational attainment: Results using sibling fixed effects. Health Economics, 19, 855-871. doi:10.1002/hec.1526

Fredriksen, K., Rhodes, J., Reddy, R., \& Way, N. (2004). Sleepless in Chicago: Tracking the Effects of Adolescent Sleep Loss During the Middle School Years. Child Development, 75, 84-95. doi:10.1111/j.1467-8624.2004.00655.x

Frey, K. S., \& Ruble, D. N. (1992). Gender constancy and the 'cost' of sex-typed behavior: A test of the conflict hypothesis. Developmental Psychology, 28, 714721. doi:10.1037/0012-1649.28.4.714

Fröjd, S. A., Nissinen, E. S., Pelkonen, M. I., Marttunen, M. J., Koivisto, A., \& KaltialaHeino, R. (2008). Depression and school performance in middle adolescent boys and girls. Journal of Adolescence, 31, 485-498. doi:10.1016/j.adolescence.2007.08.006

Ge, X., Natsuaki, M. N., \& Conger, R. D. (2006). Trajectories of depressive symptoms and stressful life events among male and female adolescents in divorced and nondivorced families. Development and Psychopathology, 18, 253-273. doi:10.1017/S0954579406060147 
Gladstone, T. G., \& Beardslee, W. R. (2000). The prevention of depression in at-risk adolescents: Current and future directions. Journal of Cognitive Psychotherapy, 14, 9-23.

Grimm, K. J. (2007). Multivariate longitudinal methods for studying developmental relationships between depression and academic achievement. International Journal of Behavioral Development, 31, 328-339. doi:10.1177/0165025407077754

Guskey, T. R. (2000). Grading policies that work against standards . . . and how to fix them. National Association of Secondary School Principals. NASSP Bulletin, 84, 20-27. doi:10.1177/019263650008462003

Haines, M. E., Norris, M. P., \& Kashy, D. A. (1996). The effects of depressed mood on academic performance in college students. Journal of College Student Development, 37, 519-526.

Halonen, A., Aunola, K., Ahonen, T., \& Nurmi, J. (2006). The role of learning to read in the development of problem behaviour: A cross-lagged longitudinal study. British Journal of Educational Psychology, 76, 517-534. doi:10.1348/000709905X51590

Hammen, C. (2005). Stress And Depression. Annual Review of Clinical Psychology, 1, 293-319. doi:10.1146/annurev.clinpsy.1.102803.143938

Hanish, L. D., \& Guerra, N. G. (2002). A longitudinal analysis of patterns of adjustment following peer victimization. Development And Psychopathology, 14, 69-89. doi:10.1017/S0954579402001049

Hanson, T., Austin, G., \& Lee-Bayha, J. (2004). Ensuring that no child is left behind: How are student health risks and resilience related to the academic progress of schools? San Francisco: WestEd.

Heath, N. L., \& Ross, S. (2000). Prevalence and expression of depressive symptomatology in students with and without learning disabilities. Learning Disability Quarterly, 23, 24-36.

Herman, K. C., Lambert, S. F., Ialongo, N. S., \& Ostrander, R. (2007). Academic pathways between attention problems and depressive symptoms among urban African American children. Journal of Abnormal Child Psychology, 35, 265-274. doi:10.1007/s10802-006-9083-2

Herman, K. C., Lambert, S. F., Reinke, W. M., \& Ialongo, N. S. (2008). Low academic competence in first grade as a risk factor for depressive cognitions and symptoms in middle school. Journal of Counseling Psychology, 55, 400-410. doi:10.1037/a0012654 
Higgins, J. \& Green, S. (editors). Cochrane Handbook for Systematic Reviews of Interventions Version 5.0.2 [updated September 2009]. The Cochrane Collaboration, 2009.

Hilt, L. M., McLaughlin, K. A., \& Nolen-Hoeksema, S. (2010). Examination of the Response Styles Theory in a community sample of young adolescents. Journal of Abnormal Child Psychology, 38, 545-556. doi:10.1007/s10802-009-9384-3

Hishinuma, E. S., Chang, J. Y., McArdle, J. J., \& Hamagami, F. (2012). Potential causal relationship between depressive symptoms and academic achievement in the Hawaiian high schools health survey using contemporary longitudinal latent variable change models. Developmental Psychology, 48, 1327-1342. doi: $10.1037 / \mathrm{a} 0026978$

Hoffman, L. W. (1972). Early childhood experiences and women's achievement motives. Journal of Social Issues, 28, 129-155. doi:10.1111/j.1540-4560.1972.tb00022.x

Houston, D. M. (2015). Revisiting the relationship between attributional style and academic performance. Journal of Applied Social Psychology, 46, 192-200. doi:10.1111/jasp.12356

Huang, C. (2015). Academic achievement and subsequent depression: A meta-analysis of longitudinal studies. Journal of Child and Family Studies, 24, 434-442. doi:10.1007/s10826-013-9855-6

Huedo-Medina, T. B., Sánchez-Meca, J., Marín-Martínez, F., \& Botella, J. (2006). Assessing heterogeneity in meta-analysis: Q statistic or $\mathrm{I}^{2}$ index? Psychological Methods, 11, 193-206. doi:10.1037/1082-989X.11.2.193

Janosz, M., Archambault, I., Pagani, L. S., Pascal, S., Morin, A. S., \& Bowen, F. (2008). Are there detrimental effects of witnessing school violence in early adolescence? Journal of Adolescent Health, 43, 600-608. doi:10.1016/j.jadohealth.2008.04.011

Kaslow, N. J., Rehm, L. P., \& Siegel, A. W. (1984). Social-cognitive and cognitive correlates of depression in children. Journal of Abnormal Child Psychology, 12, 605-620. doi:10.1007/BF00916853

Kim, S. Y., Chen, Q., Wang, Y., Shen, Y., \& Orozco-Lapray, D. (2013). Longitudinal linkages among parent-child acculturation discrepancy, parenting, parent-child sense of alienation, and adolescent adjustment in Chinese immigrant families. Developmental Psychology, 49, 900-912. doi:10.1037/a0029169

Kovacs, M. (1992). The Children's Depression Inventory (CDI) manual. Multi-Health Systems. Toronto, ON. 
Kovacs, M., \& Beck, A. T. (1978). Maladaptive cognitive structures in depression. The American Journal of Psychiatry, 135, 525-533. doi:10.1176/ajp.135.5.525

Kovacs, M., \& Devlin, B. (1998). Internalizing disorders in childhood. Journal of Child Psychology And Psychiatry, 39(1), 47-63. doi:10.1017/S0021963097001765

Kreutzer, J. S., Caplan, B., \& DeLuca, J. (2011). Encyclopedia of clinical neuropsychology. New York: Springer.

Kuncel, N. R., Crede, M., \& Thomas, L. L. (2005). The validity of self-reported grade point averages, class ranks, and test scores: A meta-analysis and review of the literature. Review of Educational Research, 75, 63-82. doi:10.3102/00346543075001063

Lakens, D., Hilgard, J., \& Staaks, J. (2016). On the reproducibility of meta-analyses: Six practical recommendations. BMC Psychology, 4

Latendresse, S. J. (2004). Perceptions of parenting among affluent youth: Exploring antecedents of middle school adjustment trajectories. (Unpublished doctoral dissertation). Columbia University, New York, NY.

Masten, A. S., Best, K. M., \& Garmezy, N. (1990). Resilience and development: Contributions from the study of children who overcome adversity. Development and Psychopathology, 2, 425-444.

Masten, A., Hubbard, J., Gest, S., Tellegen, A., Garmezy, N., \& Ramirez, M. (1999). Competence in the context of adversity: pathways to resilience and maladaptation from childhood to late adolescence. Development and Psychopathology, 11, 14369.

Masten, A. S., Roisman, G. I., Long, J. D., Burt, K. B., Obradović, J., Riley, J. R., \& ... Tellegen, A. (2005). Developmental Cascades: Linking Academic Achievement and Externalizing and Internalizing Symptoms Over 20 Years. Developmental Psychology, 41, 733-746. doi:10.1037/0012-1649.41.5.733

Mavridis, D., \& Salanti, G. (2014) .Exploring and accounting for publication bias in mental health: A brief overview of methods. Evidence-Based Mental Health, 17. 30-35.

McCarty, C. A., Mason, W. A., Kosterman, R., Hawkins, J. D., Lengua, L. J., \& McCauley, E. (2008). Adolescent school failure predicts later depression among girls. Journal of Adolescent Health, 43, 180-187.

doi:10.1016/j.jadohealth.2008.01.023 
Mcgrath, E. P. (2000). Depressive symptoms and negative self-perceptions in childhood: Cognitive distortion, academic performance, peer relationships. (Unpublished dissertation). University of California at Los Angeles, Los Angeles, CA.

Miech, R. A., Caspi, A., Moffitt, T. E., Wright, B. E., \& Silva, P. A. (1999). Low socioeconomic status and mental disorders: A longitudinal study of selection and causation during young adulthood. American Journal of Sociology, 104, 10961131. doi:10.1086/210137

Mikami, A. Y., \& Hinshaw, S. P. (2006). Resilient Adolescent Adjustment Among Girls: Buffers of Childhood Peer Rejection and Attention-Deficit/Hyperactivity Disorder. Journal of Abnormal Child Psychology, 34, 825-839. doi:10.1007/s10802-006-9062-7

Moon, W., Kwon, M., \& Chung, K. (2015) Influence of academic resilience, self-efficacy and depression on college life adjustment in Korea's nursing college students. Indian Journal of Science and Technology, 8. 1-8. doi: 10.17485/ijst/2015/v8i19/77003

Morales, J. R., \& Guerra, N. G. (2006). Effects of multiple context and cumulative stress on urban children's adjustment in elementary school. Child Development, 77, 907923. doi:10.1111/j.1467-8624.2006.00910.x

Muller, B. E., \& Erford, B. T. (2012). Choosing assessment instruments for depression outcome research with school - age youth. Journal of Counseling \& Development, 90, 208-220. doi:10.1111/j.1556-6676.2012.00026.x

Myers, K., \& Winters, N. C. (2002). Ten-year review of rating scales. II. Scales for internalizing disorders. Journal of the American Academy of Child \& Adolescent Psychiatry, 41, 634-659. doi:10.1097/00004583-200206000-00004

National Survey on Drug Use and Health, Substance Abuse and Mental Health Services Administration, 2015. Retrieved from https://www.samhsa.gov/data/sites/default/files/NSDUH-DetTabs-2015/NSDUHDetTabs-2015/NSDUH-DetTabs-2015.pdf on January 30, 2017.

Needham, B. L. (2009). Adolescent depressive symptomatology and young adult educational attainment: An examination of gender differences. Journal of Adolescent Health, 45, 179-186. doi:10.1016/j.jadohealth.2008.12.015

Nolen-Hoeksema, S. (1991). Responses to depression and their effects on the duration of depressive episodes. Journal of Abnormal Psychology, 100, 569-582. doi:10.1037/0021-843X.100.4.569 
Nolen-Hoeksema, S., \& Morrow, J. (1991). A prospective study of depression and posttraumatic stress symptoms after a natural disaster: The 1989 Loma Prieta earthquake. Journal of Personality and Social Psychology, 61, 115-121. doi:10.1037/0022-3514.61.1.115

O’Hara, M. (1995). The Cognitive Diathesis for Depression. In G. Miller (Ed.), The Behavioral High-Risk Paradigm in Psychopathology (250-270). New York, NY: Springer.

Oldehinkel, A. J., Rosmalen, J. G., Veenstra, R., Dijkstra, J. K., \& Ormel, J. (2007). Being admired or being liked: Classroom social status and depressive problems in early adolescent girls and boys. Journal of Abnormal Child Psychology, 35, 417427. doi:10.1007/s10802-007-9100-0

Patterson, G., \& Capaldi, D. (1990). A comparison of models for boys' depressed mood. In J.E. Rolf, A. Masten, D. Ciccheti, K. Neuchterlein, \& S. Weintraub (Eds.), Risk and protective factors in the development of psychopathology. Boston: Cambridge University Press.

Patterson, G. R., \& Stoolmiller, M. (1991). Replications of a dual failure model for boys' depressed mood. Journal of Consulting and Clinical Psychology, 59, 491-498. doi:10.1037/0022-006X.59.4.491

Quiroga, C. V., Janosz, M., Bisset, S., \& Morin, A. S. (2013). Early adolescent depression symptoms and school dropout: Mediating processes involving selfreported academic competence and achievement. Journal of Educational Psychology, 105, 552-560. doi:10.1037/a0031524

R Core Team (2013). R: A language and environment for statistical computing. R Foundation for Statistical Computing, Vienna, Austria.

Radloff, L. S. (1991). The use of the Center for Epidemiologic Studies Depression Scale in adolescents and young adults. Journal of Youth and Adolescence, 20, 149-166. doi:10.1007/BF01537606

Repetto, P. B. (2003). A longitudinal study of depressive symptoms among AfricanAmerican adolescents: Their patterns of change and effects on school outcomes and substance use. (Unpublished dissertation). University of Michigan, Ann Arbor, MI.

Roeser, R. W., \& Eccles, J. S. (1998). Adolescents' perceptions of middle school: Relation to longitudinal changes in academic and psychological adjustment. Journal of Research on Adolescence, 8, 123-158. doi:10.1207/s15327795jra0801_6 
Roeser, R. W., Eccles, J. S., \& Sameroff, A. J. (2000). School as a context of early adolescents' academic and social-emotional development: A summary of research findings. The Elementary School Journal, 100, 443-471. doi: 10.1086/499650

Roorda, D. L., Koomen, H. M. Y., Spilt, J. L., \& Oort, F. J. (2011). The influence of affective teacher-student relationships on students' school engagement and achievement: A meta-analytic approach. Review of Educational Research, 81, 493-529. doi:10.3102/0034654311421793

Rudolph, K. D., Lambert, S. F., Clark, A. G., \& Kurlakowsky, K. D. (2001). Negotiating the transition to middle school: The role of self-regulatory processes. Child Development, 72, 929-946. doi:10.1111/1467-8624.00325

Schwartz, D., Gorman, A. H., Duong, M. T., \& Nakamoto, J. (2008). Peer relationships and academic achievement as interacting predictors of depressive symptoms during middle childhood. Journal of Abnormal Psychology, 117, 289-299. doi:10.1037/0021-843X.117.2.289

Scott, M., Wilcox, H., Huo, Y., Turner, J. B., Fisher, P., \& Shaffer, D. (2010). SchoolBased Screening for Suicide Risk: Balancing Costs and Benefits. American Journal of Public Health, 100, 1648-1652. doi:10.2105/AJPH.2009.175224

Shahar, G., Henrich, C. C., Winokur, A., Blatt, S. J., Kuperminc, G. P., \& Leadbeater, B. J. (2006). Self-criticism and depressive symptomatology interact to predict middle school academic achievement. Journal of Clinical Psychology, 62, 147-155. doi:10.1002/jclp.20210

Sharp, L. K., \& Lipsky, M. S. (2002). Screening for depression across the lifespan: a review of measures for use in primary care settings. American Family Physician, 66, 1001-1008.

Shin, H. (2010). Does depression moderate or mediate the relations between deficits in competence and aggression?: A short-term longitudinal study of Korean children. School Psychology International, 31(4), 331-352. doi:10.1177/0143034310377139

Sterne, J., Higgins, J., \& Reeves, B. on behalf of the development group for ACROBATNRSI. (2014). A Cochrane risk of bias assessment tool: For non-randomized studies of interventions (ACROBAT-NRSI), Version 1.0.0. Available from http://www.riskofbias.info [accessed October 22, 2015].

Taylor, S., \& Tweedie, R. (1998).A non-parametric "trim and fill" method of assessing publication bias in meta-analysis. Available from 
http://citeseerx.ist.psu.edu/viewdoc/download?doi=10.1.1.54.2343\&rep=rep1\&ty pe=pdf [accessed October 22, 2015].

The role of high school teachers in preventing suicide [pamphlet]. 2012 Waltham, MA: Suicide Prevention Resource Center.

Topitzes, J., Godes, O, Mersky, J. P., Ceglarek, S. \& Reynolds, A. J. (2009). Educational success and adult health: Findings from the Chicago Longitudinal Study. Prevention Science, 10(2), 175-95.

Trost, K., \& El-Khouri, B. M. (2008). Mapping Swedish females' educational pathways in terms of academic competence and adjustment problems. Journal of Social Issues, 64, 157-174. doi:10.1111/j.1540-4560.2008.00553.x

Undheim, A. M., \& Sund, A. M. (2005). School factors and the emergence of depressive symptoms among young Norwegian adolescents. European Child \& Adolescent Psychiatry, 14, 446-453. doi:10.1007/s00787-005-0496-1

Useche, A. C. (2015). Effects of family, schools, and community contexts on children's self-regulation, competence in mathematics and reading, and social and emotional adjustment. (Unpublished dissertation). University of Florida, Gainesville, FL.

Valentine, J. C., Pigott, T. D., \& Rothstein, H. R. (2010). How many studies do you need? A primer on statistical power for meta-analysis. Journal of Educational and Behavioral Statistics, 35, 215-247. doi:10.3102/1076998609346961

van Lier, P. C., Vitaro, F., Barker, E. D., Brendgen, M., Tremblay, R. E., \& Boivin, M. (2012). Peer victimization, poor academic achievement, and the link between childhood externalizing and internalizing problems. Child Development, 83, 1775-1788. doi:10.1111/j.1467-8624.2012.01802.x

Vargas, D. A., Roosa, M. W., Knight, G. P., \& O’Donnell, M. (2013). Family and cultural processes linking family instability to Mexican American adolescent adjustment. Journal of Family Psychology, 27, 387-397. doi:10.1037/a0032863

Ventura J., Liberman, R., \& Green, M. (1998). Training and quality assurance with the Structured Clinical Interview for DSM-IV (SCID-I/P). Psychiatry Research, 79,163-173. doi:10.1016/S0165-1781(98)00038-9

Verboom, C. E., Sijtsema, J. J., Verhulst, F. C., Penninx, B. H., \& Ormel, J. (2014). Longitudinal associations between depressive problems, academic performance, and social functioning in adolescent boys and girls. Developmental Psychology, 50, 247-257. doi:10.1037/a0032547 
Viechtbauer, W. (2010). Conducting meta-analyses in R with the metafor package. Journal of Statistical Software, 36, 1-48. URL: http://www.jstatsoft.org/v36/i03/

Wang, M., Chow, A., Hofkens, T., \& Salmela-Aro, K. (2015). The trajectories of student emotional engagement and school burnout with academic and psychological development: Findings from Finnish adolescents. Learning and Instruction, 36. 57-65. doi:10.1016/j.learninstruc.2014.11.004

Weissman, M. M., Wolk, S., Goldstein, R. B., Moreau, D., Adams, P., Greenwald, S., \& ... Wickramaratne, P. (1999). Depressed adolescents grown up. Journal of the American Medical Association, 281, 1707-1713.

White JL, Moffitt TE, \& Silva PA. (1989). A prospective replication of the protective effects of IQ in subjects at high risk for juvenile delinquency. Journal of Consulting and Clinical Psychology, 57, 719-24.

Wichstrøm, L. (1999). The emergence of gender difference in depressed mood during adolescence: The role of intensified gender socialization. Developmental Psychology, 35, 232-245. doi:10.1037/0012-1649.35.1.232

Yong, M., Fleming, C. B., McCarty, C. A., \& Catalano, R. F. (2014). Mediators of the associations between externalizing behaviors and internalizing symptoms in late childhood and early adolescence. The Journal of Early Adolescence, 34, 9671000. doi:10.1177/0272431613516827 
Table 1: Database Search Strategy

1. To search for article that included a depression measure:

Depression measures were administered to the child or adolescent study participants, either as the independent measure as reported as one variable among many others reported as components of a larger survey.

Search terms: Depress* or internaliz* or mood* or affect*

2. To search for article that included academic achievement measures:

A measure of academic achievement must have been reported. This could include GPA, standardized test score(s), grade retention records, or graduation rates.

Search terms: Achieve* or attend* or Grade* or GPA or Graduation or Retent* or Academic*

\section{Types of Participants}

This meta-analysis examined correlations reported for school-aged children and adolescents at multiple time points. Participants of studies included in this meta-analysis varied in age from five to eighteen years. The studies included students from a variety of settings and populations, including clinical and non-clinical populations, special education settings, and children or adolescents experiencing co-morbid issues in either physical or mental health arenas. General population samples and samples consisting exclusively of special populations (e.g. students who met criteria for special education services, had chronic diseases, or had co-morbid mental health diagnoses) were included. Details related to distinguishing characteristics of study participants were provided.

Search terms: Child* or Student* or Adolesc*

\section{Types of Research Designs}

Only quantitative studies were included in this meta-analysis. Studies could be of any type of design, including correlational, causal, experimental, and longitudinal.

Search terms: quantitative or longitudinal or prospective or retrospective or time points

\section{Types of Outcomes}

To be included in this meta-analysis, studies must have either included a correlation of depression and achievement provided as part of a correlation matrix. 
Table 2: Abstract Screening Guide

\begin{tabular}{|c|c|}
\hline Study Inclusion Criteria & \\
\hline 1. Does the study include a measure of depression? & \begin{tabular}{|l} 
1. No \\
2. Yes \\
3. Can't tell/unsure \\
IF NO, THEN STOP
\end{tabular} \\
\hline 1. Does the study include a measure of academic achievement? & \begin{tabular}{|l} 
1. No \\
2. Yes \\
3. Can't tell/unsure \\
IF NO, THEN STOP
\end{tabular} \\
\hline $\begin{array}{l}\text { 1. Does the study include school-aged children and adolescents, } \\
\text { ranging in age from five to eighteen years? }\end{array}$ & \begin{tabular}{|l} 
1. No \\
2. Yes \\
3. Can't tell/unsure \\
IF NO, THEN STOP
\end{tabular} \\
\hline $\begin{array}{l}\text { 1. Does the study report on an empirical study with quantitative } \\
\text { results? }\end{array}$ & $\begin{array}{l}\text { 1. No } \\
\text { 2. Yes } \\
\text { 3. Can't tell/unsure } \\
\text { IF NO, THEN STOP }\end{array}$ \\
\hline $\begin{array}{l}\text { 1. Does the study include a metric of the statistical relationship } \\
\text { between depression and achievement? }\end{array}$ & \begin{tabular}{|l} 
1. No \\
2. Yes \\
3. Can't tell/unsure \\
IF NO, THEN STOP
\end{tabular} \\
\hline
\end{tabular}


Table 3: Coding Guide for Depression \& Academic Achievement Meta-Analysis

\begin{tabular}{|c|c|}
\hline $\begin{array}{l}\text { Report } \\
\text { Characteristics }\end{array}$ & Response \\
\hline 1. Report ID Number & \\
\hline $\begin{array}{l}\text { 2. Author (First } \\
\text { author last name) }\end{array}$ & \\
\hline 3. Publication year & \\
\hline 4. Study source & $\begin{array}{l}\text { 0. Electronic search } \\
\text { 1. Researcher }\end{array}$ \\
\hline 5. Type of publication & $\begin{array}{l}\text { 0. Journal article } \\
\text { 1. Dissertation/thesis } \\
\text { 2. Conference poster or presentation } \\
\text { 3. Other } \\
\text { 99. Unknown }\end{array}$ \\
\hline Study Design & \\
\hline $\begin{array}{l}\text { 6. Participant } \\
\text { Selection }\end{array}$ & $\begin{array}{l}\text { 0. Random from local population } \\
\text { 1. Convenience } \\
\text { 2. Current symptoms } \\
\text { 3. Other } \\
\text { 99. Unknown }\end{array}$ \\
\hline $\begin{array}{l}\text { 7. Lapse between first } \\
\text { and last data waves } \\
\text { (months) }\end{array}$ & \\
\hline $\begin{array}{l}\text { Sample } \\
\text { Demographics }\end{array}$ & \\
\hline
\end{tabular}




\begin{tabular}{|c|c|}
\hline 8. Participant Age & $\begin{array}{l}\text { Range } \\
\text { Mean } \\
\text { SD }\end{array}$ \\
\hline 9.Participant Gender & $\begin{array}{l}\% \text { Female: } \\
\text { NR - Not reported }\end{array}$ \\
\hline $\begin{array}{l}\text { 10. Participant } \\
\text { ethnicity }\end{array}$ & $\begin{array}{l}\text { Report } \% \text { in each category: } \\
\text { 1. Caucasian __ } \\
\text { 2. African American __ } \\
\text { 3. Hispanic __ subgroup: } \\
\text { 4. Asian American __ subgroup: } \\
\text { 5. Native American___subgroup: } \\
\text { 6. Other__ subgroup: } \\
\text { 99. Not reported }\end{array}$ \\
\hline 11.Country of study & $\begin{array}{l}\text { 1. United States } \\
\text { 2. Canada }\end{array}$ \\
\hline $\begin{array}{l}\text { 12.Date range of } \\
\text { study }\end{array}$ & $\begin{array}{l}\text { Start: } \\
\text { Finish: }\end{array}$ \\
\hline 13.Attrition & $\begin{array}{l}\text { Percent retained: } \\
\text { 99. Not reported }\end{array}$ \\
\hline 14.Attrition bias & $\begin{array}{l}\text { Description of how attrition bias was assessed: } \\
\text { 99. Not reported }\end{array}$ \\
\hline Depression Measure & \\
\hline
\end{tabular}




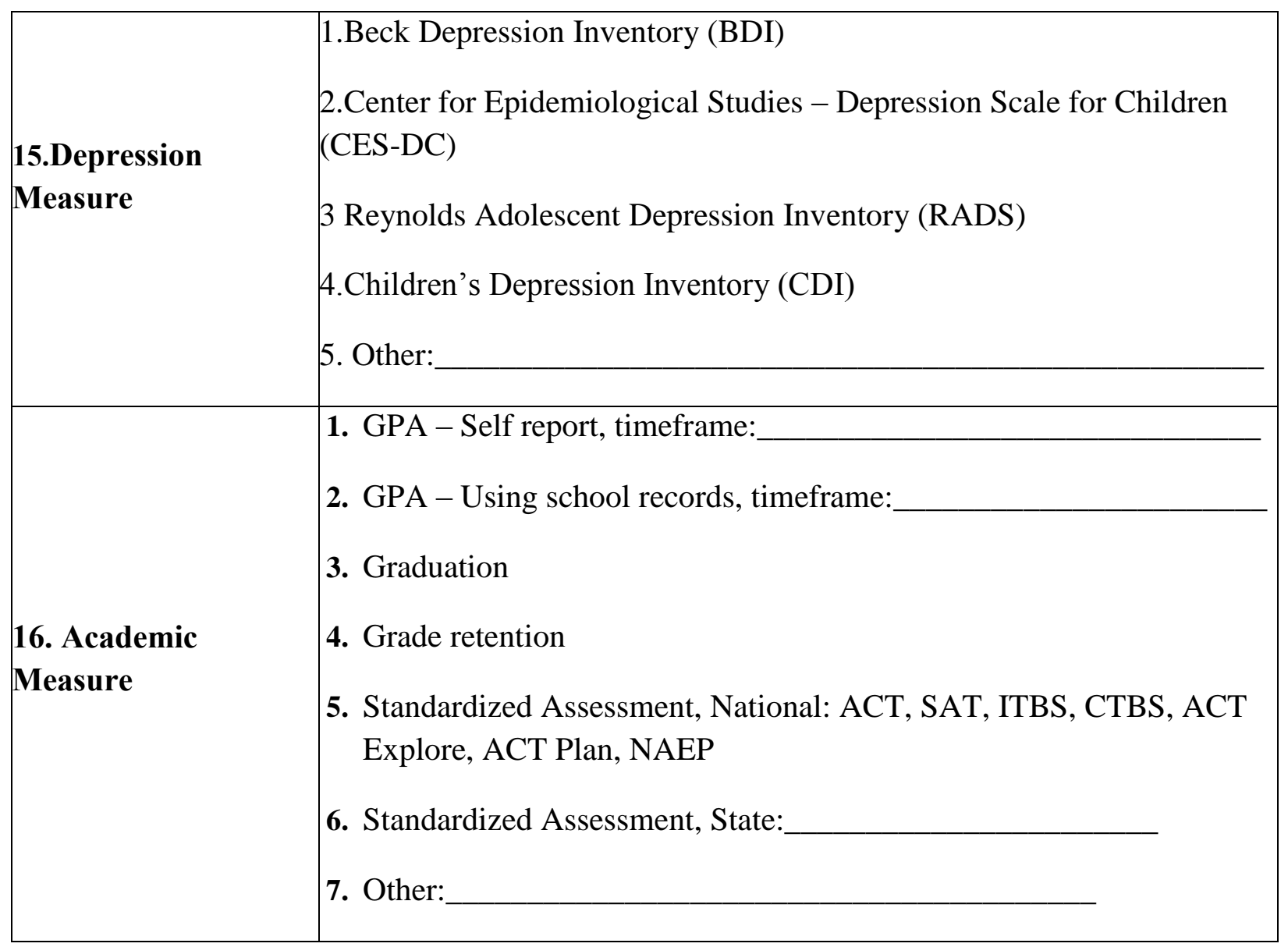




\begin{tabular}{|c|c|c|c|c|}
\hline & 1. Beck (BDI) & 1. Beck (BDI) & 1. Beck (BDI) & 1. Beck (BDI) \\
\hline & 2. CES-DC & 2. CES-DC & 2. CES-DC & 2. CES-DC \\
\hline & 3. RADS & 3. RADS & 3. RADS & 3. RADS \\
\hline & 4. CDI & 4. CDI & 4. CDI & 4. CDI \\
\hline & 5. Other: & 5. Other: & 5. Other: & 5. Other: \\
\hline & 1. GPA-self & 7. GPA-self & 7. GPA-self & 7. GPA-self \\
\hline & 2. GPA-records & 8.GPA-records & 8.GPA-records & 8.GPA-records \\
\hline & 3 Graduation & 9.Graduation & 9.Graduation & 9.Graduation \\
\hline $\begin{array}{l}\text { 17. Please provide th } \\
\text { name(s) of the test(s) }\end{array}$ & 10 Petention & 10.Retention & 10.Retention & 10.Retention \\
\hline if available. & $11 \wedge \mathrm{CT}$ & 11. ACT & 11. ACT & 11. ACT \\
\hline & 11. AC 1 & 12.SAT & 12.SAT & 12.SAT \\
\hline & 12.SAI & 13.ITBS & 13.ITBS & 13.ITBS \\
\hline & 14.CTBS & 14.CTBS & 14.CTBS & 14.CTBS \\
\hline & 15.ACT Explore & 15.ACT Explore & 15.ACT Explore & 15.ACT Explore \\
\hline & 16.ACT Plan & 16.ACT Plan & 16.ACT Plan & 16.ACT Plan \\
\hline & 17.NAEP & 17.NAEP & 17.NAEP & 17.NAEP \\
\hline & 18. Other: & 18. Other: & 18. Other: & 18. Other: \\
\hline $\begin{array}{l}\text { 18. Is the validity of } \\
\text { the data collection }\end{array}$ & 1. Yes & 1. Yes & 1. Yes & 1. Yes \\
\hline $\begin{array}{l}\text { tools/methods } \\
\text { reported? }\end{array}$ & 2. No & 2. No & 2. No & 2. No \\
\hline
\end{tabular}




\begin{tabular}{|c|c|c|c|c|}
\hline $\begin{array}{l}\text { 19. What (construct) } \\
\text { validity procedures } \\
\text { were reported? }\end{array}$ & $\begin{array}{l}\text { 1. Previous } \\
\text { validity research } \\
\text { cited } \\
\text { 2. Common } \\
\text { practice (studies } \\
\text { using similar } \\
\text { assessment } \\
\text { procedures cited) } \\
\text { 3. Preliminary } \\
\text { investigation } \\
\text { (e.g., pilot study, } \\
\text { item ratings by } \\
\text { experts) } \\
\text { 4. Other (please } \\
\text { specify) }\end{array}$ & $\begin{array}{l}\text { 1. Previous } \\
\text { validity research } \\
\text { cited } \\
\text { 2. Common } \\
\text { practice (studies } \\
\text { using similar } \\
\text { assessment } \\
\text { procedures cited) } \\
\text { 3. Preliminary } \\
\text { investigation } \\
\text { (e.g., pilot study, } \\
\text { item ratings by } \\
\text { experts) } \\
\text { 4. Other (please } \\
\text { specify) }\end{array}$ & $\begin{array}{l}\text { 1. Previous } \\
\text { validity research } \\
\text { cited } \\
\text { 2. Common } \\
\text { practice (studies } \\
\text { using similar } \\
\text { assessment } \\
\text { procedures cited) } \\
\text { 3. Preliminary } \\
\text { investigation } \\
\text { (e.g., pilot study, } \\
\text { item ratings by } \\
\text { experts) } \\
\text { 4. Other (please } \\
\text { specify) }\end{array}$ & $\begin{array}{l}\text { 1. Previous } \\
\text { validity research } \\
\text { cited } \\
\text { 2. Common } \\
\text { practice (studies } \\
\text { using similar } \\
\text { assessment } \\
\text { procedures cited) } \\
\text { 3. Preliminary } \\
\text { investigation } \\
\text { (e.g., pilot study, } \\
\text { item ratings by } \\
\text { experts) } \\
\text { 4. Other (please } \\
\text { specify }\end{array}$ \\
\hline $\begin{array}{l}\text { 20. Is the reliability of } \\
\text { the data collection } \\
\text { tools/methods } \\
\text { reported? }\end{array}$ & $\begin{array}{l}\text { 1. Yes } \\
\text { 2. No }\end{array}$ & $\begin{array}{l}\text { 1. Yes } \\
\text { 2. No }\end{array}$ & $\begin{array}{l}\text { 1. Yes } \\
\text { 2. No }\end{array}$ & $\begin{array}{l}\text { 1. Yes } \\
\text { 2. No }\end{array}$ \\
\hline $\begin{array}{l}\text { 21. What reliability } \\
\text { coefficient was } \\
\text { reported? }\end{array}$ & $\begin{array}{l}\text { 1. Cronbach' } \\
\text { alpha } \\
\text { 2. Test-retest } \\
\text { 3. Interrater } \\
\text { reliability } \\
\text { 4. Other (please } \\
\text { specify) }\end{array}$ & $\begin{array}{l}\text { 1. Cronbach' } \\
\text { alpha } \\
\text { 2. Test-retest } \\
\text { 3. Interrater } \\
\text { reliability } \\
\text { 4. Other (please } \\
\text { specify) }\end{array}$ & $\begin{array}{l}\text { 1. Cronbach' } \\
\text { alpha } \\
\text { 2. Test-retest } \\
\text { 3. Interrater } \\
\text { reliability } \\
\text { 4. Other (please } \\
\text { specify) }\end{array}$ & $\begin{array}{l}\text { 1. Cronbach' } \\
\text { alpha } \\
\text { 2. Test-retest } \\
\text { 3. Interrater } \\
\text { reliability } \\
\text { 4. Other (please } \\
\text { specify) }\end{array}$ \\
\hline $\begin{array}{l}22 . \text { What was the } \\
\text { value for the metric } \\
\text { in } 19 ?\end{array}$ & & & & \\
\hline
\end{tabular}




\begin{tabular}{|l|l|}
\hline $\begin{array}{l}\text { 23. Correlation for } \\
\text { depression at baseline } \\
\text { on achievement at } \\
\text { time point two } \\
\text { controlling for } \\
\text { achievement at } \\
\text { baseline) }\end{array}$ & $\begin{array}{l}\text { 1. } \\
\text { 24. Correlation for } \\
\text { achievement at } \\
\text { baseline on } \\
\text { depression at time } \\
\text { point two (controlling } \\
\text { for depression at } \\
\text { baseline) }\end{array}$ \\
\hline $\begin{array}{l}\text { 25. Correlation } \\
\text { matrix provided }\end{array}$ & \begin{tabular}{l} 
1. Not reported \\
\hline
\end{tabular} \\
\hline
\end{tabular}




\section{Table 4: References for Studies Used in Meta-Analysis}

Chang, E. S., Greenberger, E., Chen, C., Heckhausen, J., \& Farruggia, S. P. (2010). Nonparental adults as social resources in the transition to adulthood. Journal of Research On Adolescence, 20, 1065-1082.

Chen, R., \& Simons-Morton, B. (2009). Concurrent changes in conduct problems and depressive symptoms in early adolescents: A developmental person-centered approach. Development and Psychopathology, 21, 285-307.

Chen, X., Yang, F., \& Wang, L. (2013). Relations between shyness-sensitivity and internalizing problems in Chinese children: Moderating effects of academic achievement. Journal of Abnormal Child Psychology, 41, 825-836.

Colarossi, L. G. (2000, August). Gender differences in social support from parents, teachers, and peers: Implications for adolescent development. (Unpublished doctoral dissertation). University of Michigan, Ann Arbor, MI.

Cunningham, J. N., Kliewer, W., \& Garner, P. W. (2009). Emotion socialization, child emotion understanding and regulation, and adjustment in urban African American families: Differential associations across child gender. Development and Psychopathology, 21, 261-283.

Denault, A., Poulin, F., \& Pedersen, S. (2009). Intensity of participation in organized youth activities during the high school years: Longitudinal associations with adjustment. Applied Developmental Science, 13, 74-87.

Fredriksen, K., Rhodes, J., Reddy, R., \& Way, N. (2004). Sleepless in Chicago: Tracking the Effects of Adolescent Sleep Loss During the Middle School Years. Child Development, 75, 84-95.

Halonen, A., Aunola, K., Ahonen, T., \& Nurmi, J. (2006). The role of learning to read in the development of problem behaviour: A cross-lagged longitudinal study. British Journal of Educational Psychology, 76, 517-534.

Janosz, M., Archambault, I., Pagani, L. S., Pascal, S., Morin, A. S., \& Bowen, F. (2008). Are there detrimental effects of witnessing school violence in early adolescence? Journal of Adolescent Health, 43, 600-608.

Kim, S. Y., Chen, Q., Wang, Y., Shen, Y., \& Orozco-Lapray, D. (2013). Longitudinal linkages among parent-child acculturation discrepancy, parenting, parent-child sense of alienation, and adolescent adjustment in Chinese immigrant families. Developmental Psychology, 49, 900-912. 
Latendresse, S. J. (2004). Perceptions of parenting among affluent youth: Exploring antecedents of middle school adjustment trajectories. (Unpublished doctoral dissertation). Columbia University, New York, NY.

Mcgrath, E. P. (2000). Depressive symptoms and negative self-perceptions in childhood: Cognitive distortion, academic performance, peer relationships. (Unpublished dissertation). University of California at Los Angeles, Los Angeles, CA.

Mikami, A. Y., \& Hinshaw, S. P. (2006). Resilient Adolescent Adjustment Among Girls: Buffers of Childhood Peer Rejection and Attention-Deficit/Hyperactivity Disorder. Journal of Abnormal Child Psychology, 34, 825-839.

Morales, J. R., \& Guerra, N. G. (2006). Effects of Multiple Context and Cumulative Stress on Urban Children's Adjustment in Elementary School. Child Development, 77, 907-923.

Repetto, P. B. (2003). A longitudinal study of depressive symptoms among AfricanAmerican adolescents: Their patterns of change and effects on school outcomes and substance use. (Unpublished dissertation). University of Michigan, Ann Arbor, MI.

Roeser, R. W., \& Eccles, J. S. (1998). Adolescents' perceptions of middle school: Relation to longitudinal changes in academic and psychological adjustment. Journal of Research on Adolescence, 8, 123-158.

Rudolph, K. D., Lambert, S. F., Clark, A. G., \& Kurlakowsky, K. D. (2001). Negotiating the transition to middle school: The role of self-regulatory processes. Child Development, 72, 929-946.

Schwartz, D., Gorman, A. H., Duong, M. T., \& Nakamoto, J. (2008). Peer relationships and academic achievement as interacting predictors of depressive symptoms during middle childhood. Journal of Abnormal Psychology, 117, 289-299.

Shin, H. (2010). Does depression moderate or mediate the relations between deficits in competence and aggression?: A short-term longitudinal study of Korean children. School Psychology International, 31(4), 331-352. doi:10.1177/0143034310377139

Trost, K., \& El-Khouri, B. M. (2008). Mapping Swedish females' educational pathways in terms of academic competence and adjustment problems. Journal of Social Issues, 64, 157-174.

Useche, A. C. (2015). Effects of family, schools, and community contexts on children's self-regulation, competence in mathematics and reading, and social and emotional adjustment. (Unpublished dissertation). University of Florida, Gainesville, FL. 
van Lier, P. C., Vitaro, F., Barker, E. D., Brendgen, M., Tremblay, R. E., \& Boivin, M. (2012). Peer victimization, poor academic achievement, and the link between childhood externalizing and internalizing problems. Child Development, 83, 1775-1788.

Vargas, D. A., Roosa, M. W., Knight, G. P., \& O’Donnell, M. (2013). Family and cultural processes linking family instability to Mexican American adolescent adjustment. Journal of Family Psychology, 27, 387-397.

Verboom, C. E., Sijtsema, J. J., Verhulst, F. C., Penninx, B. H., \& Ormel, J. (2014). Longitudinal associations between depressive problems, academic performance, and social functioning in adolescent boys and girls. Developmental Psychology, 50, 247-257.

Wang, M., Chow, A., Hofkens, T., \& Salmela-Aro, K. (2015). The trajectories of student emotional engagement and school burnout with academic and psychological development: Findings from Finnish adolescents. Learning and Instruction, 36, 57-65.

Yong, M., Fleming, C. B., McCarty, C. A., \& Catalano, R. F. (2014). Mediators of the associations between externalizing behaviors and internalizing symptoms in late childhood and early adolescence. The Journal of Early Adolescence, 34, 967-1000 
Table 5: Publication and Methodology Information for Included Studies

\begin{tabular}{|c|c|c|c|c|c|c|c|c|c|c|c|c|c|c|c|c|c|c|c|}
\hline 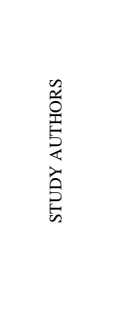 & 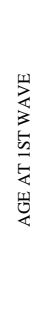 & 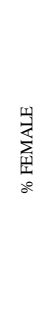 & 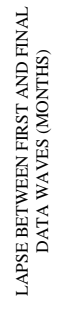 & 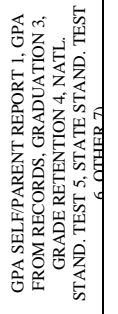 & 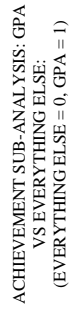 & 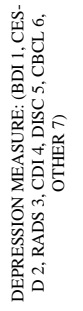 & 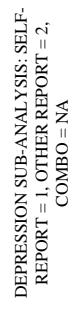 & 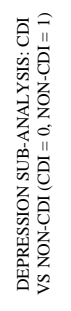 & $=$ & 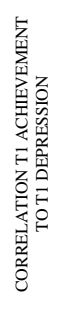 & 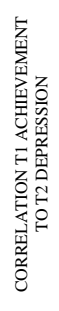 & 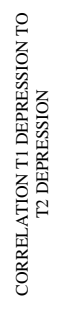 & 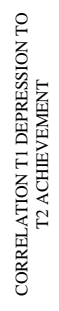 & 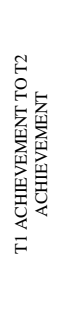 & 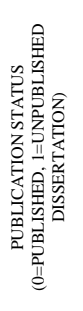 & 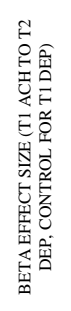 & 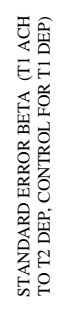 & 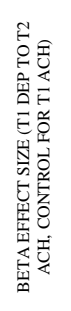 & 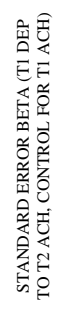 \\
\hline $\begin{array}{c}\text { Chang, } \\
\text { Greenberger, } \\
\text { Chen et al. } \\
(2010) \\
\end{array}$ & 18 & 60 & 12 & 1 & 1 & 2 & 1 & 1 & 754 & -0.19 & -0.12 & 0.5 & -0.13 & 0.29 & 0 & -0.027 & 0.0359 & -0.074 & 0.0310 \\
\hline $\begin{array}{l}\text { Chen \& } \\
\text { Simons- } \\
\text { Martin } \\
\text { (2009) }\end{array}$ & $\begin{array}{c}11.0 \\
0\end{array}$ & 54 & 24 & 7 & 0 & 5 & 1 & 1 & 108 & -0.15 & 0.03 & 0.25 & -0.16 & 0.19 & 1 & 0.052 & 0.0935 & -0.137 & 0.0855 \\
\hline $\begin{array}{l}\text { Chen, Yang } \\
\& \text { Wang } \\
(2013) \\
\end{array}$ & 9.33 & 49.5 & 12 & 2 & 1 & 4 & 1 & 0 & 1155 & -0.26 & -0.25 & 0.56 & -0.23 & -0.04 & 0 & -0.112 & 0.0245 & -0.240 & 0.0329 \\
\hline $\begin{array}{c}\text { Colarossi } \\
\text { females } \\
(2000) \\
\end{array}$ & 6.6 & 100 & 12 & 1 & 1 & 7 & 1 & 1 & 125 & -0.13 & -0.12 & 0.57 & -0.14 & 0.7 & 1 & -0.048 & 0.0611 & -0.054 & 0.0585 \\
\hline $\begin{array}{c}\text { Colarossi } \\
\text { males (2000) }\end{array}$ & 6.6 & 0 & 12 & 1 & 1 & 7 & 1 & 1 & 92 & -0.15 & -0.06 & 0.54 & -0.06 & 0.69 & 1 & 0.018 & 0.0951 & 0.031 & 0.0850 \\
\hline $\begin{array}{l}\text { Cunningham, } \\
\text { Kliewer, \& } \\
\text { Garner } \\
(2009) \\
\text { females } \\
\end{array}$ & $\begin{array}{c}11.2 \\
9\end{array}$ & 50 & 6 & 1 & 1 & 7 & $\mathrm{NA}$ & 1 & 35 & -0.38 & -0.39 & 0.72 & 0.22 & 0.7 & 0 & -0.113 & 0.1264 & 0.596 & 0.0897 \\
\hline $\begin{array}{l}\text { Cunningham, } \\
\text { Kliewer, \& } \\
\text { Garner } \\
\text { (2009) males }\end{array}$ & $\begin{array}{c}11.2 \\
9\end{array}$ & 50 & 6 & 1 & 1 & 7 & $\mathrm{NA}$ & 1 & 34 & 0.11 & 0.24 & 0.72 & 0.22 & 0.58 & 0 & 0.163 & 0.1313 & 0.161 & 0.1370 \\
\hline $\begin{array}{l}\text { Denault, } \\
\text { Poulin, \& } \\
\text { Pederson } \\
\text { (2009) }\end{array}$ & $\frac{12.3}{8}$ & 59 & 36 & 2 & 1 & 4 & 1 & 0 & 362 & -0.26 & -0.07 & 0.47 & -0.17 & 0.62 & 0 & 0.066 & 0.0531 & -0.011 & 0.0387 \\
\hline $\begin{array}{l}\text { Fredriksen, } \\
\text { Rhodes, } \\
\text { Reddy \& } \\
\text { Way (2004) }\end{array}$ & 11.5 & 49.6 & 24 & 1 & 1 & 4 & 1 & 0 & 2259 & -0.27 & -0.15 & 0.39 & -0.25 & 0.48 & 0 & -0.049 & 0.0211 & -0.128 & 0.0156 \\
\hline $\begin{array}{c}\text { Halonen, } \\
\text { AUnola, } \\
\text { Ahonen, } \\
\text { Nurmi (2006) } \\
\end{array}$ & 6.25 & 46.9 & 30 & 7 & 0 & 7 & 2 & 1 & 196 & -0.19 & -0.11 & 0.36 & -0.21 & 0.54 & 0 & -0.056 & 0.0665 & -0.112 & 0.0606 \\
\hline $\begin{array}{l}\text { Janosz, } \\
\text { Archambault, } \\
\text { Paganai, } \\
\text { Pascal, } \\
\text { Morin, \& } \\
\text { Bowen } \\
\text { (2008) } \\
\end{array}$ & 12.8 & 48.4 & 10 & 1 & 1 & 1 & 1 & 1 & 1104 & -0.06 & -0.14 & 0.59 & -0.06 & 0.55 & 0 & -0.108 & 0.0246 & -0.029 & 0.0243 \\
\hline $\begin{array}{l}\text { Kim, Chen, } \\
\text { Wang, Shen, } \\
\text { \& Orozco- } \\
\text { Lapray } \\
\text { (2013) }\end{array}$ & $\begin{array}{c}13.0 \\
4\end{array}$ & 54.4 & 48 & 7 & 0 & 2 & 1 & 1 & 379 & -0.16 & -0.16 & 0.35 & -0.16 & 0.74 & 0 & -0.109 & 0.0475 & -0.036 & 0.0324 \\
\hline
\end{tabular}




\begin{tabular}{|c|c|c|c|c|c|c|c|c|c|c|c|c|c|c|c|c|c|c|c|}
\hline $\begin{array}{c}\text { Latendresse } \\
(2004) \\
\text { females } \\
\end{array}$ & 11.5 & 100 & 24 & 2 & 1 & 4 & 1 & 0 & 138 & -0.38 & -0.25 & 0.5 & -0.19 & 0.74 & 1 & -0.073 & 0.0793 & 0.101 & 0.055 \\
\hline $\begin{array}{l}\text { Latendresse } \\
(2004) \text { males }\end{array}$ & 11.5 & 0 & 24 & 2 & 1 & 4 & 1 & ${ }^{0}$ & 152 & -0.23 & -0.33 & 0.52 & -0.18 & 0.75 & 1 & -0.224 & 0.0699 & -0.008 & 0.0532 \\
\hline $\begin{array}{c}\text { McGrath } \\
(2000)\end{array}$ & 9.5 & 46.8 & 36 & 2 & 1 & 4 & $\mathrm{NA}$ & 0 & 227 & -0.22 & -0.13 & 0.58 & -0.25 & 0.49 & 1 & -0.003 & 0.0615 & -0.145 & 0.064 \\
\hline $\begin{array}{c}\text { Mikami \& } \\
\text { Hinshaw } \\
(2006)\end{array}$ & 9.5 & 100 & 54 & 7 & 0 & 7 & $\mathrm{NA}$ & 1 & 209 & -0.46 & -0.27 & 0.54 & -0.39 & 0.82 & 0 & -0.032 & 0.0728 & -0.016 & 0.0480 \\
\hline $\begin{array}{l}\text { Morales \& } \\
\text { Guerra } \\
\text { (2006) } \\
\text { (average of } \\
\text { math and } \\
\text { reading) } \\
\end{array}$ & 10.5 & 50 & 24 & 5 & 0 & 6 & 2 & 1 & 2745 & -0.03 & -0.11 & 0.10 & -0.10 & 0.26 & 0 & -0.104 & 0.0197 & -0.095 & 0.017 \\
\hline $\begin{array}{l}\text { Repetto } \\
(2003)\end{array}$ & $\begin{array}{c}14.4 \\
9\end{array}$ & 50.8 & 48 & 2 & 1 & 7 & 1 & 1 & 850 & -0.089 & -0.045 & 0.028 & -0.026 & 0.006 & 1 & -0.045 & 0.0409 & 0.101 & 0.0386 \\
\hline $\begin{array}{c}\text { Roeser \& } \\
\text { Eccles (1998) }\end{array}$ & 12.5 & 50 & 24 & 2 & 1 & 7 & 1 & 1 & 1046 & -0.09 & -0.26 & 0.36 & 0.12 & 0.79 & 0 & -0.233 & 0.0304 & -0.051 & 0.0208 \\
\hline $\begin{array}{l}\text { Rudolph, } \\
\text { Lambert, } \\
\text { Clark, \& } \\
\text { Kulrakowsky } \\
\text { (2001) males }\end{array}$ & 11.2 & 51.1 & 6.5 & 2 & 1 & 4 & 1 & 0 & 329 & -0.35 & -0.21 & 0.58 & -0.22 & 0.72 & 0 & -0.001 & 0.0533 & 0.028 & 0.0476 \\
\hline $\begin{array}{c}\text { Schwartz, } \\
\text { Gorman, } \\
\text { Duong, \& } \\
\text { Nakanoto } \\
\text { (2008) } \\
\end{array}$ & 9.1 & 47.9 & 12 & 2 & 1 & 4 & 1 & 0 & 199 & -0.32 & -0.42 & 0.48 & -0.34 & 0.68 & 0 & $\begin{array}{l}-0.295 \\
\end{array}$ & 0.0571 & -0.134 & 0.0568 \\
\hline Shin (2010) & 11.5 & 55 & 6 & 7 & 0 & 4 & 1 & 0 & 455 & -0.45 & -0.41 & 0.71 & -0.43 & 0.8 & 0 & -0.108 & 0.0450 & -0.086 & 0.0377 \\
\hline $\begin{array}{c}\text { Trost \& El- } \\
\text { Khouri } \\
(2008)\end{array}$ & 10 & 100 & 36 & 2 & 1 & 7 & 1 & 1 & 479 & -0.14 & -0.24 & 0.25 & -0.14 & 0.8 & 0 & -0.204 & 0.0490 & -0.027 & 0.036 \\
\hline $\begin{array}{c}\text { Useche } \\
\text { (2015) } \\
\text { (average of } 4 \\
\text { samples) }\end{array}$ & 5.5 & 49 & 36 & 7 & 0 & 7 & 2 & 1 & 12652 & -0.19 & -0.20 & 0.57 & -0.19 & 0.65 & 1 & $\begin{array}{l}-0.099 \\
\end{array}$ & 0.0082 & -0.071 & 0.0068 \\
\hline $\begin{array}{l}\text { Van Lier, } \\
\text { Vitaro, } \\
\text { Barker, } \\
\text { Brendgen, } \\
\text { Tremblay, \& } \\
\text { Boivin } \\
\text { (2012) } \\
\end{array}$ & 7.1 & 48.8 & 12 & 7 & 0 & 7 & 2 & 1 & 1558 & -0.38 & -0.38 & 0.38 & -0.33 & 0.77 & 1 & -0.276 & 0.0278 & -0.046 & 0.0177 \\
\hline $\begin{array}{c}\text { Vargas, } \\
\text { Roosa, } \\
\text { Knight \& } \\
\text { OnDonnell } \\
\text { (2013) }\end{array}$ & 10.4 & 49 & 24 & 2 & 1 & 5 & 1 & 1 & 749 & 0.16 & 0.09 & 0.45 & -0.1 & 0.51 & 0 & 0.025 & 0.0344 & 0.027 & 0.033 \\
\hline $\begin{array}{c}\text { Verboom, } \\
\text { Sijtsema, } \\
\text { Vernulst, } \\
\text { Pennix, \& } \\
\text { Ormel (2014) }\end{array}$ & $\begin{array}{c}11.0 \\
9\end{array}$ & 50.8 & 24 & 7 & 0 & 7 & 2 & 1 & 2230 & -0.12 & -0.08 & 0.41 & 0.06 & 0.18 & 0 & -0.030 & 0.0208 & 0.082 & 0.0260 \\
\hline $\begin{array}{l}\text { Wang, Chow, } \\
\text { Hoftens, \& } \\
\text { SalmelaAdro } \\
(2015) \\
\end{array}$ & $\begin{array}{c}15.9 \\
8\end{array}$ & 52.2 & 24 & 1 & 1 & 7 & 1 & 1 & 362 & -0.02 & -0.08 & 0.42 & 0.04 & 0.66 & 0 & -0.076 & 0.0485 & -0.034 & 0.039 \\
\hline $\begin{array}{c}\text { Yong, } \\
\text { Fleming, } \\
\text { McCarty, \& } \\
\text { Catalano } \\
\text { (2014) }\end{array}$ & 7 & 46.8 & 24 & 6 & 0 & 7 & 1 & 1 & 983 & -0.07 & -0.07 & 0.61 & -0.05 & 0.68 & 0 & -0.025 & 0.0236 & 0.001 & 0.0238 \\
\hline
\end{tabular}




\section{Table 6: Trim and Fill Analysis}

Trim and Fill analysis (T1 ACH $->$ T2 DEP, controlling for T1 DEP) (looking for missing studies on $\underline{\text { the left side) }}$

Estimated number of missing studies on the left side: $5(\mathrm{SE}=3.5923)$

Model Results:

estimate se zval pval ci.lb ci.ub

$\begin{array}{llllll}-0.1024 & 0.0180 & -5.6789 & <.0001 & -0.1377 & -0.0670\end{array} * * *$

Signif. codes: 0 ‘***’ 0.001 '**’ 0.01 '*’ 0.05 ‘’ $0.1^{\prime \prime}$ ' 1

Trim and Fill analysis (T1 ACH -> T2 DEP, controlling for T1 DEP) (looking for missing studies on $\underline{\text { the right side) }}$

Estimated number of missing studies on the right side: $0(\mathrm{SE}=2.5178)$

Model Results:

estimate se zval pval ci.lb ci.ub

$\begin{array}{llllll}-0.0824 & 0.0177 & -4.6637 & <.0001 & -0.1171 & -0.0478 \quad * * *\end{array}$

Trim and Fill analysis (T1 DEP -> T2 ACH, controlling for T1 ACH) (looking for missing studies on $\underline{\text { the left side) }}$

Estimated number of missing studies on the left side: $0(\mathrm{SE}=3.0103)$

Model Results:

estimate se zval pval ci.lb ci.ub

$\begin{array}{llllll}-0.0242 & 0.0214 & -1.1339 & 0.2568 & -0.0661 & 0.0177\end{array}$

Trim and Fill analysis (T1 DEP -> T2 ACH, controlling for T1 ACH) (looking for missing studies on $\underline{\text { the right side) }}$

Estimated number of missing studies on the right side: $6(\mathrm{SE}=3.5916)$

Model Results:

estimate se zval pval ci.lb ci.ub

$\begin{array}{llllll}0.0077 & 0.0223 & 0.3423 & 0.7321 & -0.0361 & 0.0514\end{array}$ 


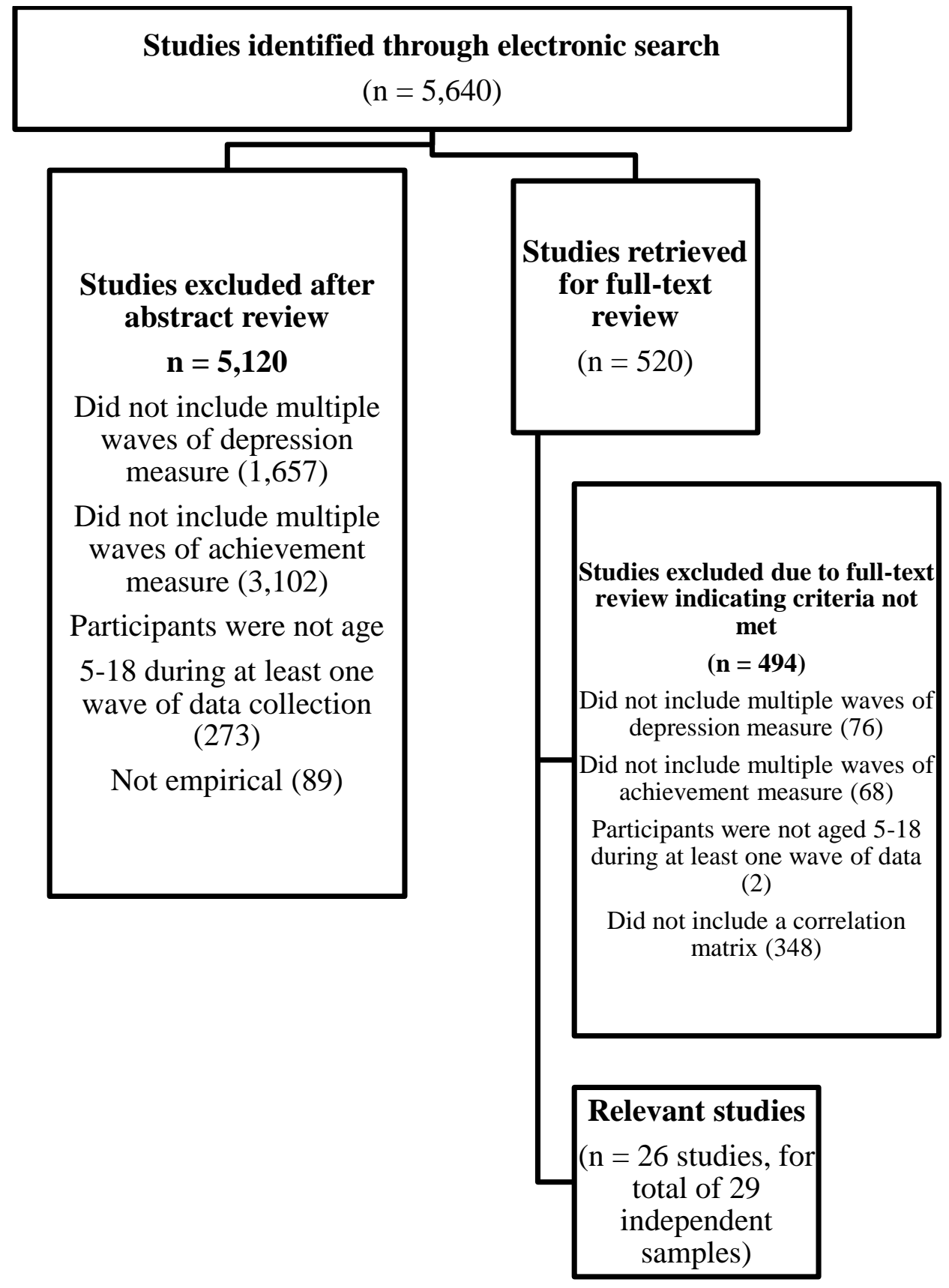

Figure 1. Screening Results Flowchart 


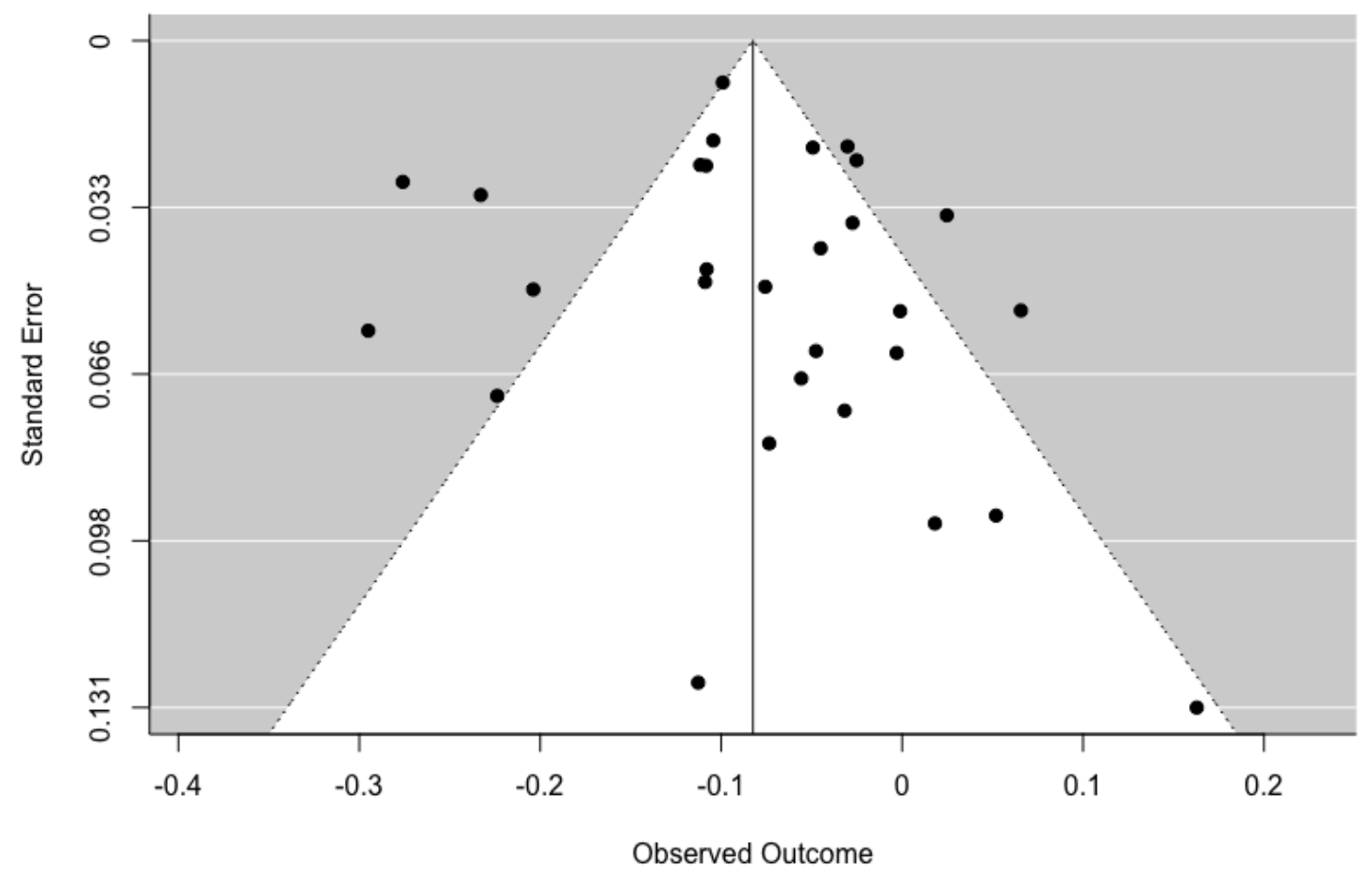

Figure 2. Funnel Plot of Achievement to Depression 


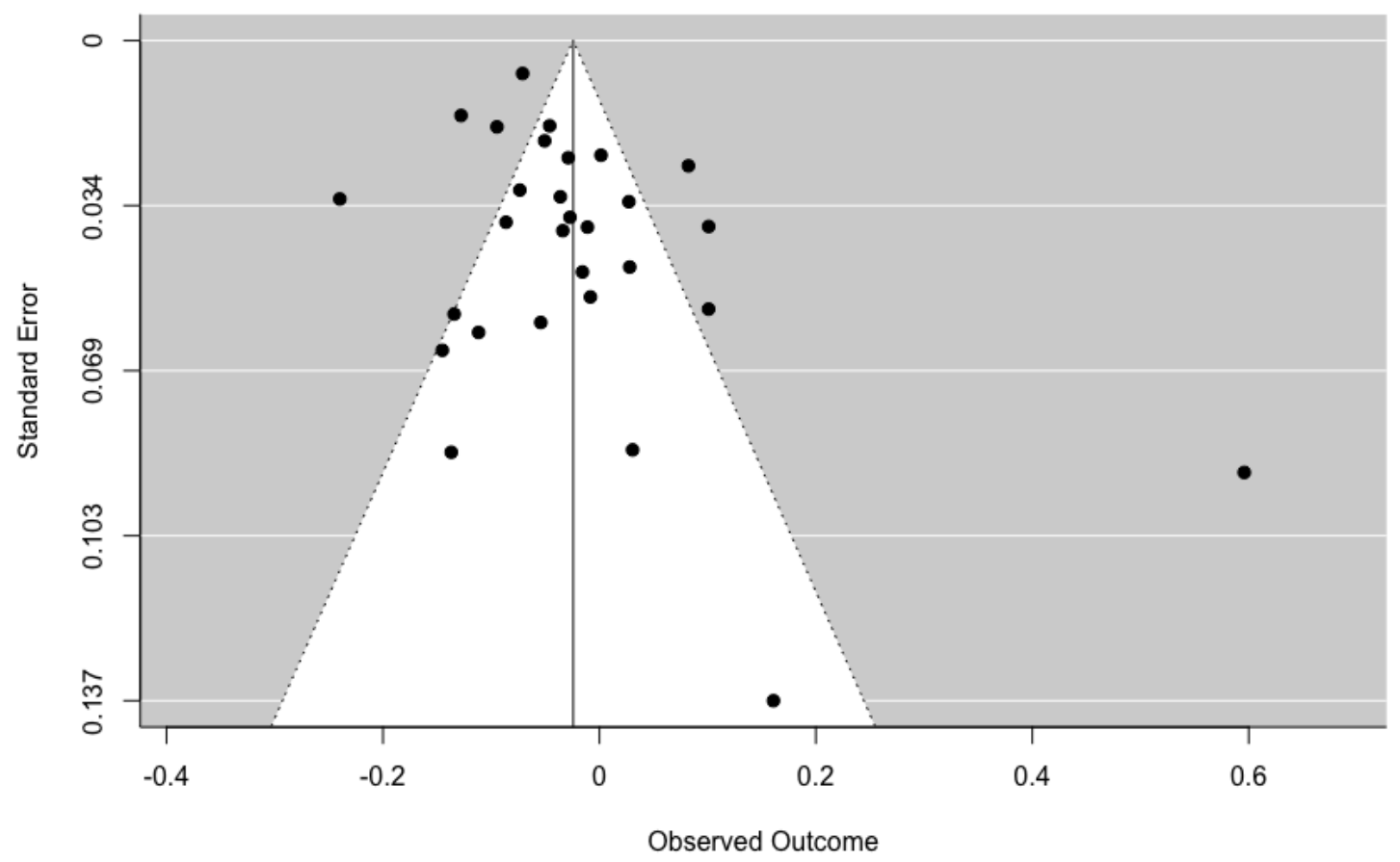

Figure 3: Funnel Plot of Depression to Achievement 


\section{CURRICULUM VITA \\ RACHEL ELIZABETH BUEHNER, M.Ed. \\ Licensed Psychological Associate}

\section{Contact Information}

$\underline{\text { Rachel.Buehner@ky.gov }}$

\section{Licenses Held}

Licensed Psychological Associate, Commonwealth of Kentucky, License \#138908

\section{Education}

2017

2009

2003

\section{Awards}

2016

2014

2011
Ph.D. in Counseling Psychology

University of Louisville

Mentors: Dr. Patrick Pössel and Dr. Jeffrey Valentine

Dissertation "A Meta-Analysis of the Longitudinal Relationship

Between Adolescent Depression and Achievement"

Master of Education in Counseling Psychology

University of Louisville

Mentor: Dr. Patrick Pössel

\section{Bachelor of Arts in Psychology}

University of Louisville

Mentor: Dr. Barbara Burns

Employee of the Month for the Kentucky Correctional Institution for Women, September 2016

National Register of Health Services Psychologists New Psychologist Trainee Register Credentialing Scholarship

"On the Spot" Award for Provision of Collateral Services to Families in Need

Seven Counties Services 
"On the Spot" Award for Planning of an Employee Retreat Seven Counties Services

Distinguished Service Award for Advancement of the Field American Statistical Association

2002

Outstanding Performance Award for Classified and Professional/Administrative Staff (Honorable Mention) Presented by University President Dr. James Ramsey University of Louisville

\section{Employment and Training History}

2014-2017

Psychologist (Master's Level)

Kentucky Correctional Institution for Women 300 Ash Avenue, Pewee Valley, KY 40058

Commonwealth of Kentucky Department of Corrections

Supervisor: Brian King, Psy.D., (502) 241-8454, ext. 2201

$2013-2014$

Pre-Doctoral Intern Jefferson County Internship Consortium, Louisville, KY Training Director: David Finke, Ph.D.

Asst. Training Dir./ Supervisor: Erin Jenkins Baker, Psy.D.

2009 - $2013 \quad$ Practicum Student/Therapist, Seven Counties Services Supervisors: Elizabeth Jackson, Ph.D., \& Scott Berry, Ph.D.

$2009-2010$

Administrative Clerk to Ginger Crumbo, Psy.D. drginger@drginger.net

$2007-2010$

Counseling Practicum Student/Counselor St. Raphael the Archangel School Supervisor: Colleen Pittman, M.Ed., cpittman@iglou.com Licensed Doctoral Supervisor: Ginger Crumbo, Psy. D.

Fall 2007

Psychological Assessment Practicum Student Archdiocese of Louisville Licensed Doctoral Supervisor: Ginger Crumbo, Psy.D. drginger@drginger.net 


\section{Teaching Experience}

Spring 2010 - 2013 Adjunct Instructor

Human Services Program

Jefferson Community College

Louisville, Kentucky

Courses taught at Jefferson Community College include "Introduction to Human Services" (one section taught) and "Theories and Techniques of Human Services" (six sections taught).

\section{Professional Memberships and Committee Participation}

American Psychological Association

Kentucky Psychological Association

Communication Committee of the Kentucky Psychological Association, 2013 - 2017

Kentucky Psychological Association Internal Audit Committee, 2017

Kentucky Dept. of Corrections Polypharmacy Working Group

Diversity Committee, University of Louisville Department of Education and Counseling Psychology, 2012 - 2013

Seven Counties Services Workplace Improvement Team, 2011-2013

Retreat Planning Committee, Seven Counties Services, 2011-2012

Chair, Communication Committee of the University of Louisville School of Public Health and Information Sciences, 2008-2009

Committee Member, Student Affairs Advisory Group, University of Louisville, 2006-2009

\section{Publications}

Cummins, R., \& Shelton, S. (2012). Reflections on the early career psychologists' mentoring program. The Kentucky Psychologist. Autumn 2012. 